\title{
Organic matter mineralization in sediment of a coastal freshwater lake and response to salinization
}

\author{
Richard W. Canavan ${ }^{\text {a,* }}$, Caroline P. Slomp a , Parisa Jourabchi a, Philippe Van Cappellen ${ }^{\text {a }}$, \\ Anniet M. Laverman ${ }^{a}$, Gerard A. van den Berg ${ }^{b}$ \\ a Department of Earth Sciences-Geochemistry, Faculty of Geosciences, Utrecht University, P.O. Box 80.021, 3508 TA Utrecht, The Netherlands \\ ${ }^{\mathrm{b}}$ Kiwa Water Research, P.O. Box 1072, 3430 BB Nieuwegein, The Netherlands
}

Received 9 September 2005; accepted in revised form 3 March 2006

\begin{abstract}
Solid phase and pore water chemical data collected in a sediment of the Haringvliet Lake are interpreted using a multi-component reactive transport model. This freshwater lake, which was formed as the result of a river impoundment along the southwestern coast of the Netherlands, is currently targeted for restoration of estuarine conditions. The model is used to assess the present-day biogeochemical dynamics in the sediment, and to forecast possible changes in organic carbon mineralization pathways and associated redox reactions upon salinization of the bottom waters. Model results indicate that oxic degradation (55\%), denitrification (21\%), and sulfate reduction $(17 \%)$ are currently the main organic carbon degradation pathways in the upper $30 \mathrm{~cm}$ of sediment. Unlike in many other freshwater sediments, methanogenesis is a relatively minor carbon mineralization pathway $(5 \%)$, because of significant supply of soluble electron acceptors from the well-mixed bottom waters. Although ascorbate-reducible Fe(III) mineral phases are present throughout the upper $30 \mathrm{~cm}$ of sediment, the contribution of dissimilatory iron reduction to overall sediment metabolism is negligible. Sensitivity analyses show that bioirrigation and bioturbation are important processes controlling the distribution of organic carbon degradation over the different pathways. Model simulations indicate that sulfate reduction would rapidly suppress methanogenesis upon seawater intrusion in the Haringvliet, and could lead to significant changes in the sediment's solid-state iron speciation. The changes in Fe speciation would take place on time-scales of 20-100 years.

(C) 2006 Elsevier Inc. All rights reserved.
\end{abstract}

\section{Introduction}

The degradation of organic matter in sediments drives the release of nutrients and pollutants from sediments to surface waters, and can profoundly influence the biogeochemical cycling of $\mathrm{C}, \mathrm{N}, \mathrm{O}, \mathrm{S}, \mathrm{P}, \mathrm{Fe}, \mathrm{Mn}$, and trace metals in aquatic environments (Hamilton-Taylor et al., 1996; Wetzel, 2001). Organic carbon $\left(\mathrm{C}_{\text {org }}\right)$ oxidation in sediments is coupled to the utilization of terminal electron acceptors (TEAs), primarily $\mathrm{O}_{2}, \mathrm{NO}_{3}{ }^{-}, \mathrm{Mn}$-(hydr)oxides, $\mathrm{Fe}$-(hydr)oxides, and $\mathrm{SO}_{4}{ }^{2-}$. When these TEAs are completely consumed, degradation of $\mathrm{C}_{\text {org }}$ continues via meth-

\footnotetext{
* Corresponding author.

E-mail address: R.Canavan@geo.uu.nl (R.W. Canavan).
}

anogenesis. The corresponding $\mathrm{C}_{\text {org }}$ degradation reactions, often referred to as the primary redox reactions, roughly succeed one another vertically in the order of decreasing free energy yield (Froelich et al., 1979). In sediments receiving large inputs of reactive organic matter, however, the various mineralization processes may exhibit significant overlap (Wersin et al., 1991; Canfield et al., 1993; Holmer and Storkholm, 2001). The primary redox reactions also produce reduced species (e.g., $\mathrm{NH}_{4}^{+}, \mathrm{Fe}^{2+}, \mathrm{H}_{2} \mathrm{~S}, \mathrm{CH}_{4}$ ), which can participate in other, so-called secondary, redox reactions. The network of primary and secondary redox reactions usually leads to a characteristic zonation of redox conditions in sediments.

The relative importance of the different primary redox reactions depends on the availability of both the organic matter and the TEAs. Key determining factors are the 
input fluxes of $\mathrm{C}_{\text {org }}$ and TEAs from the overlying water column, organic matter quality, rates of physical transport of solids and solutes in the sediment, and rates of secondary redox reactions that regenerate or consume TEAs. In eutrophic lake sediments, TEAs are frequently in low supply relative to the influx of $\mathrm{C}_{\text {org }}$. In these depositional settings, aerobic degradation of $\mathrm{C}_{\text {org }}$ may be limited by $\mathrm{O}_{2}$ consumption due to secondary oxygenation reactions, particularly the oxidation of $\mathrm{CH}_{4}$ (Sweerts et al., 1991). Furthermore, reactive $\mathrm{Fe}$ (III) mineral phases are often preserved in fresh water sediments (Wersin et al., 1991; Gallon et al., 2004; Hyacinthe and Van Cappellen, 2004), while low $\mathrm{SO}_{4}{ }^{2-}$ concentrations in freshwater environments limit sulfate reduction (Holmer and Storkholm, 2001). As a consequence, methanogenesis is generally a dominant $\mathrm{C}_{\text {org }}$ degradation process (Capone and Kiene, 1988; Peretyazhko et al., 2005). However, efficient recycling of TEAs may increase the importance of specific primary redox pathways, as observed for sulfate reduction (Urban et al., 1994) and dissimilatory iron reduction (Thomsen et al., 2004) in oligotrophic lake sediments.

Total organic carbon mineralization rates, and the relative contributions of the different primary redox reactions, can be estimated directly via incubation experiments (Canfield et al., 1993; Dauwe et al., 2001; Thomsen et al., 2004), or they can be quantified by applying reactive transport models (RTMs) to geochemical data sets. Multi-component RTMs have been used successfully to estimate kinetic parameters and rates of primary and secondary redox reactions (Van Cappellen and Wang, 1996). These models have mostly been applied to marine sediments, and less frequently to freshwater sediments (Van Cappellen and Wang, 1995; Furrer and Wehrli, 1996; van den Berg et al., 2000).

The focus of this study is to quantify the rates of organic carbon mineralization in the sediment of Haringvliet Lake (The Netherlands). Reaction rates are determined both experimentally and with a RTM calibrated with pore water and sediment chemistry data. In addition, the RTM is used to examine how biogeochemical cycling may change in response to salinization induced by restoration of estuarine conditions in the lake.

\section{Study site}

Haringvliet Lake is a eutrophic freshwater lake, which was created as a result of the damming of the mouth of an estuary in 1970 (Fig. 1), as part of the Dutch Delta Project (Ferguson and Wolff, 1984). Prior to dam construction, the Haringvliet was a tidal estuary and an outlet of the Meuse-Rhine river system to the North Sea. The closure of the Haringvliet caused physical and chemical changes in the water body, including the rapid conversion to a freshwater lake, increased shore-line erosion, and the accumulation of river derived suspended matter (Ferguson and Wolff, 1984; Smit et al., 1997; van Wijngaarden et al., 2002). The latter has negatively affected the benthic fauna, because of the high pollutant loading associated with sus-



Fig. 1. The sampling location in Haringvliet Lake. The inset map shows The Netherlands with a box denoting the location of the detail section. The Rhine-Meuse river complex flows into the lake from the east, and the lake discharges through the dam at the western limit of the lake.

pended matter from the Rhine and Meuse (ReinholdDudok van Heel and den Besten, 1999). Thermal stratification and bottom water anoxia are not observed due to the shallow water depth and short residence time of water in the lake (Smit et al., 1997).

Current Dutch water management policy aims at the development of a broad range of tidal systems with a high ecological diversity (de Jonge and de Jong, 2002). Within the framework of this policy, a proposed partial restoration of estuarine conditions in the Haringvliet would begin in 2008 and be achieved by changing the opening and closing of the gates in the dam that separates the lake from the North Sea (Anonymous, 1998). The present study is part of a larger effort to assess how benthic biogeochemistry and ecology may respond to a possible future intrusion of seawater in the lake. We selected a location near the dam as our study site (Fig. 1), within the area that will be most impacted by salinization. This location is characterized by fine-grained sediments, which are the main reservoir of pollutants in the lake, as reported for other Rhine and Meuse-derived sediments in the Netherlands (van den Berg et al., 1999, 2001). The water depth at the sampling site is $7.5 \mathrm{~m}$.

\section{Methods}

\subsection{Sample collection}

Field sampling was carried out in November 2001, September 2002, and April 2003. These sampling times are referred to in the text as fall, late-summer, and spring, respectively. Sediment was collected using a cylindrical box corer (31 cm i.d.) deployed from RV Navicula. Each box core contained approximately $40 \mathrm{~cm}$ of surface sediment and $30 \mathrm{~cm}$ of overlying water. Sub-cores were taken with polycarbonate tubes $(10 \mathrm{~cm}$ i.d.). Sub-cores for pore water and solid phase analyses were taken from a single 
box core. The sub-cores were immediately sectioned in a $\mathrm{N}_{2}$ purged glove box on board the ship in a temperature-controlled laboratory. Sediment was centrifuged at $2500 \mathrm{~g}$ for $10-30 \mathrm{~min}$ in polyethylene tubes to collect pore water.

\subsection{Pore water analyses}

After centrifugation, tubes were transferred to a $\mathrm{N}_{2}$ purged glove box, the pore water was filtered through 0.2 or $0.45 \mu \mathrm{m}$ pore size filters, and $\mathrm{pH}$ was measured immediately with an ion selective field effect transistor electrode (ISFET, Sentron). Pore water was then sub-divided and preserved for analysis in the laboratory. Sub-samples for $\mathrm{NO}_{3}^{-}, \mathrm{NH}_{4}^{+}, \mathrm{Cl}^{-}$, and $\mathrm{SO}_{4}{ }^{2-}$ were stored frozen until analysis: $\mathrm{NO}_{3}{ }^{-}$and $\mathrm{NH}_{4}{ }^{+}$were determined colorimetrically on a nutrient auto-analyzer (Bran and Luebbe), $\mathrm{Cl}^{-}$and $\mathrm{SO}_{4}{ }^{2-}$ were determined by ion chromatography (Dionex DX-120). Sub-samples for total dissolved $\mathrm{Mn}$ and $\mathrm{Fe}$ were acidified with $\mathrm{HNO}_{3}\left(50 \mu \mathrm{l}\right.$ conc. suprapur $\mathrm{HNO}_{3}$ per ml) and stored at $4{ }^{\circ} \mathrm{C}$ until analysis by ICP-MS (Agilent 7500 series). Sub-samples for major constituents, such as $\mathrm{Na}^{+}$, were preserved with $\mathrm{HNO}_{3}(10 \mu$ l conc. suprapur $\mathrm{HNO}_{3}$ per $\mathrm{ml}$ ) and stored at $4{ }^{\circ} \mathrm{C}$ until analysis by ICPOES (Perkin Elmer Optima 3000).

During the spring and late-summer sampling, sulfide (Cline, 1969) and alkalinity (Sarazin et al., 1999) were determined on board the ship colorimeterically using a UV-Vis spectrophotometer (Unicam UV1). Sub-samples for sulfide analysis included a base preservative $(10 \mu \mathrm{l}$ $1 \mathrm{M} \mathrm{NaOH}$ per ml). A sulfide pore water profile was also measured in late-summer using the Diffusive Gradient in Thin Films (DGT) method (Teasdale et al., 1999; Naylor et al., 2004). With this method, sulfide is determined by quantifying the color change resulting from the reaction of a $\mathrm{AgI}$ (yellow) containing gel with pore water sulfide, producing $\mathrm{AgS}_{2}$ (black). Sulfide concentrations in the pore water were calculated using the calibration of Naylor et al. (2004).

During fall sampling, dissolved inorganic carbon (DIC) was measured as the difference of total and organic dissolved carbon. The latter was measured with a Shimadzu TOC-5050A analyzer. Dissolved oxygen microprofiles were obtained on board using a Clark-type oxygen sensor with an internal reference and a guard cathode (Revsbech, 1989) attached to a micromanipulator. Perspex cores (4.2 $\mathrm{cm}$ i.d.) with $10 \mathrm{~cm}$ sediment and $5 \mathrm{~cm}$ overlying water were collected from a box core. The surface of each core was sparged with air and profiling was completed within 30 min of core retrieval.

\subsection{Solid phase analyses}

The water content and density of the sediment were determined from the weight loss upon freeze drying. Grain size was measured using a laser diffraction technique (Malvern Mastersizer $\mathrm{S}$ ) on freeze dried sediment, after $\mathrm{HCl}$ and $\mathrm{H}_{2} \mathrm{O}_{2}$ pre-treatment. Total carbon, total sulfur, and organic carbon (following carbonate removal with $1 \mathrm{M}$ $\mathrm{HCl}$ ) were determined on freeze-dried sediments using an elemental analyzer (LECO SC-1440H). Total $\mathrm{Mn}$ and $\mathrm{Fe}$ were determined by ICP-MS after $\mathrm{HF}-\mathrm{HClO}_{4}-\mathrm{HNO}_{3}$ digestion of freeze dried sediment as described in Hyacinthe and Van Cappellen (2004). Near-neutral pH ascorbate extractions were performed on wet sediment following the procedure of Hyacinthe and Van Cappellen (2004). This extraction releases the most chemically reactive reducible pool of Mn and Fe (Kostka and Luther, 1994; Hyacinthe and Van Cappellen, 2004).

Acid volatile sulfide (AVS) was determined by the method described in van den Berg et al. (1998), with some modifications. Approximately $1 \mathrm{~g}$ of wet sediment was transferred to a reaction vessel in an Ar filled glove bag. The reaction vessel was weighed and then attached to an Ar purged analysis train. Samples were acidified with $10 \mathrm{ml} 6 \mathrm{M} \mathrm{HCl}$ and purged for $1 \mathrm{~h}$. The $\mathrm{H}_{2} \mathrm{~S}$ released from the sample was trapped in a $1 \mathrm{M} \mathrm{NaOH}$ solution and determined colorimetrically (Cline, 1969).

Chloropigments were extracted from wet sediment with $90 \%$ acetone, at a 1:2 sediment to solvent ratio. Sediments were mixed with a vortex stirrer and sonicated for $10 \mathrm{~min}$ (Sun et al., 1991). Following sonication, the extractant was collected by centrifugation and stored at $0{ }^{\circ} \mathrm{C}$ until analysis. Determination of Chlorophyll- $a(\mathrm{Chl}-a)$ and Pheophytin- $a$ (Pheo- $a$ ) in the extracts was performed spectrophotometrically (APHA, 1985). Solid phase data presented are from the late-summer sampling unless otherwise indicated.

\subsection{Rate measurements}

Rates of total carbon mineralization were determined by monitoring $\mathrm{CO}_{2}$ accumulation in the headspace of oxic and anoxically incubated slurries, following the procedure of Dauwe et al. (2001). Slurries containing approximately $20 \mathrm{ml}$ wet sediment and $10 \mathrm{ml}$ filtered, de-oxygenated lake water were placed in $100 \mathrm{ml}$ glass vials sealed with rubber septa. The vials were shaken and the headspace was purged for $10 \mathrm{~min}$ with either air for oxic incubations, or $\mathrm{N}_{2}$ for anoxic incubations. The purging procedure was repeated three times for each vial. The $\mathrm{CO}_{2}$ concentration in the headspace was monitored using gas chromatography. Potential rates of denitrification and sulfate reduction were determined using flow-through reactors (FTRs), following methods described in detail elsewhere (Roychoudhury et al., 2003; Pallud and Van Cappellen, 2006).

\section{Model formulation}

The model presented in this paper follows the general approach outlined in Van Cappellen and Wang (1996); this section therefore focuses on the implementation of processes described in more recent studies, and the derivation of parameter values and boundary conditions from field data. The reaction-transport model calculations were carried out 
with the Biogeochemical Reaction Network Simulator (BRNS), a flexible modeling environment for one-dimensional simulations (Regnier et al., 2003; Aguilera et al., 2005; Jourabchi et al., 2005). In the BRNS, the chemical species, reaction stoichiometries, kinetic parameters, boundary conditions, and transport parameters are specified by the user through a MAPLE software or web-based interface (Chilakapati, 1995; Amberg et al., 1999; Regnier et al., 2002, 2003). An executable program, which consists of a set of standard routines for iteratively solving the reaction and transport equations, is then generated automatically. The model output consists of the species concentrations, reaction rates, and fluxes as a function of depth. Both steady-state and transient simulations can be performed.

\subsection{Species and reactions}

The model developed here considers 24 chemical species (Table 1) and 32 reaction pathways (Table 2). The mineralization of organic carbon is modeled using the multi-G approach (Westrich and Berner, 1984). Three pools of organic carbon are included in the model: OM1, the most reactive $\mathrm{C}_{\mathrm{org}}$ fraction, $\mathrm{OM} 2$, a less reactive fraction, and OM3, the non-reactive or refractory pool. The decomposition kinetics are first-order and controlled by the rate constants, $k_{\mathrm{OM} 1}$ and $k_{\mathrm{OM} 2}$. To account for increased degradation efficiencies of $\mathrm{C}_{\text {org }}$ under oxic versus anoxic conditions (e.g. Hedges and Keil, 1995; Kristensen, 2000; Dauwe et al., 2001; Bastviken et al., 2004; Meile and Van Cappellen, 2005), a dimensionless acceleration factor (accel) is included (Table 2).

Total $\mathrm{C}_{\text {org }}$ decomposition is distributed over the different degradation pathways following the approach of Van Cappellen and Wang (1996). This approach is based on a Michaelis-Menten kinetic formulation for the utilization of the TEAs, where a set of limiting concentration values $\left(K_{\mathrm{m}}\right)$ determines the fractions $\left(f_{\mathrm{TEA}}\right)$ of total $\mathrm{C}_{\text {org }}$ occurring

Table 1

Solutes and solids included in the model and their boundary conditions at the sediment surface

\begin{tabular}{lclc}
\hline Solutes & $\mu \mathrm{M}$ & Solids & $\mu \mathrm{mol} \mathrm{cm}{ }^{-2} \mathrm{yr}^{-1}$ \\
\hline $\mathrm{O}_{2}$ & 238 & $\mathrm{OM} 1$ & 630 \\
$\mathrm{NO}_{3}{ }^{-}$ & 154 & $\mathrm{OM} 2$ & 315 \\
$\mathrm{SO}_{4}{ }^{2-}$ & 638 & $\mathrm{OM} 3$ & 546 \\
$\mathrm{NH}_{4}{ }^{+}$ & 14.5 & $\mathrm{MnO}{ }_{2} \mathrm{~A}$ & 4.2 \\
$\mathrm{Mn}^{2+}$ & 0.2 & $\mathrm{Fe}(\mathrm{OH})_{3} \mathrm{~A}$ & 14.7 \\
$\mathrm{Fe}^{2+}$ & 0 & $\mathrm{MnO}{ }_{2} \mathrm{~B}$ & 2.1 \\
$\mathrm{H}_{2} \mathrm{~S}_{1} \mathrm{HS}^{-}$ & 0 & $\mathrm{Fe}(\mathrm{OH})_{3} \mathrm{~B}$ & 23.1 \\
$\mathrm{HCO}_{3}{ }^{-}$ & 405 & $\mathrm{FeS}$ & 0 \\
$\mathrm{CO}_{2}{ }^{2-}$ & 17.3 & $\mathrm{FeS}$ & 0 \\
$\mathrm{CO}_{3}{ }^{2-}$ & $\mathrm{NH}_{4}^{+}$ads & 0 \\
$\mathrm{CH}_{4}(\mathrm{aq}),(\mathrm{g})$ & 0 & & \\
$\mathrm{H}^{+}$ & 0 & & \\
\hline
\end{tabular}

Solute concentrations are determined experimentally or estimated, solid fluxes are derived from model fitting (see Section 4.3).

${ }^{\mathrm{a}} \mathrm{pH}$ units. via the various degradation pathways. The redox zonation and overlap between primary redox processes has been successfully reproduced for a variety of subsurface environments using this approach (Van Cappellen and Wang, 1995, 1996; Hunter et al., 1998; Berg et al., 2003; Fossing et al., 2004).

The rate parameters controlling $\mathrm{C}_{\text {org }}$ decomposition ( $k_{\mathrm{OM} 1}, k_{\mathrm{OM} 2}$, and accel) were constrained by the experimental rate measurements and the model fits (Table 3). Initial guesses of the parameter values were based on the global relationships reported by Tromp et al. (1995). The value of the acceleration factor imposed in the model calculations $($ accel $=25)$ falls in between that obtained from the $\mathrm{CO}_{2}$ production rates in oxic versus anoxic slurry incubations (oxic:anoxic $=17$ ), and the maximum potential rates of denitrification and sulfate reduction measured in FTRs on intact sediment slices (denitrification:sulfate reduction =34). The $K_{\mathrm{m}}$ values of Van Cappellen and Wang (1995) were used, except for dissimilatory iron reduction, for which a higher $K_{\mathrm{m}}$ value had to be imposed to reproduce the limited microbial reduction of iron in the sediment.

In sediments, the build-up of methane may result in the formation of gas bubbles. This process is simulated using the approach of Martens et al. (1998), where methanogenesis produces $\mathrm{CH}_{4}(\mathrm{aq})$ until the pore water concentration equals the saturation concentration. Further methanogenesis then produces $\mathrm{CH}_{4}(\mathrm{~g})$. A unitless parameter, $f_{\mathrm{m}}$, is introduced to switch between $\mathrm{CH}_{4}(\mathrm{aq})$ and $\mathrm{CH}_{4}(\mathrm{~g})$ production (R12 and R13, Table 2):

$f_{\mathrm{m}}=1-\frac{1}{\left(1+\mathrm{e}^{\delta}\right)} \quad$ with $\delta=S_{\mathrm{m}}\left(\mathrm{CH}_{4}(\mathrm{aq})-\mathrm{CH}_{4}^{*}\right)$,

where $\mathrm{CH}_{4}{ }^{*}$ is the methane solubility $(\mathrm{mM})$ and $S_{\mathrm{m}}$ $\left(\mathrm{mM}^{-1}\right)$ is an adjustable parameter. This formulation insures that the value of $f_{\mathrm{m}}$ rapidly approaches 1 when $\mathrm{CH}_{4}(\mathrm{aq})>\mathrm{CH}_{4}{ }^{*}$, and 0 when $\mathrm{CH}_{4}(\mathrm{aq})<\mathrm{CH}_{4}{ }^{*}$. The use of a continuous $f_{\mathrm{m}}$ function Eq. (1) avoids numerical oscillations in model output. It is assumed that $\mathrm{CH}_{4}(\mathrm{~g})$ is transported to the sediment-water interface (SWI) without further reaction in the sediment. For the sake of simplicity, effects of gas production on porosity and compaction are not considered in the model.

All secondary redox reactions are assigned bimolecular rate laws (Table 2). As in Berg et al. (2003), two pools of reactive $\mathrm{Mn}$ and $\mathrm{Fe}$ oxides are considered. The first, or bioavailable, pool can be reduced microbially as well as chemically, while the second pool can only be reduced chemically. Chemical reduction of reactive $\mathrm{Mn}$ and $\mathrm{Fe}$ oxides by sulfide is assumed to yield $\mathrm{SO}_{4}{ }^{2-}$ as the final oxidized S-species (R22-R25, Table 2). That is, intermediate sulfur species are assumed to be short-lived (Elsgaard and Jørgensen, 1992) and are not represented explicitly. Initial values of secondary reaction rate constants were obtained from previous studies (Table 3), and then adjusted to obtain better fits to the field data. In particular, the values of $k_{\mathrm{tsmn}}, k_{\mathrm{tsfe}}$, and $k_{\mathrm{ch} 4 \mathrm{so} 4}$ used here are lower than reported previously. 
Table 2

The reaction network and kinetic formulations used in the model

\begin{tabular}{|c|c|c|c|}
\hline Description & Reaction & $\begin{array}{l}\text { Kinetic or equilibrium } \\
\text { formulation }\end{array}$ & $\begin{array}{l}\text { Reaction } \\
\text { number }\end{array}$ \\
\hline 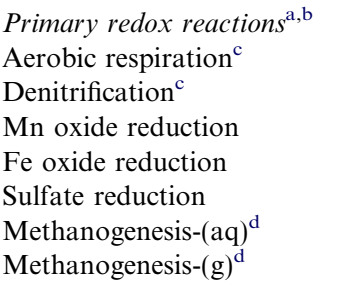 & $\begin{array}{l}\mathrm{OM}+x \mathrm{O}_{2}+(-y+2 z) \mathrm{HCO}_{3} \rightarrow(x-y+2 z) \mathrm{CO}_{2}+y \mathrm{NH}_{4}^{+}+z \mathrm{HPO}_{4}{ }^{2-}+(x+2 y+2 z) \mathrm{H}_{2} \mathrm{O} \\
\mathrm{OM}+0.8 x \mathrm{NO}_{3}^{-} \rightarrow 0.4 x \mathrm{~N}_{2}+(0.2 x-y+2 z) \mathrm{CO}_{2}+(0.8 x+y-2 z) \mathrm{HCO}_{3}^{-}+y \mathrm{NH}_{4}^{+}+z \mathrm{HPO}_{4}{ }^{2-}+(0.6 x-y+2 z) \mathrm{H}_{2} \mathrm{O} \\
\mathrm{OM}+2 x \mathrm{MnO}_{2}+(3 x+y-2 z) \mathrm{CO}_{2}+(x+y-2 z) \mathrm{H}_{2} \mathrm{O} \rightarrow 2 x \mathrm{Mn}^{2+}+(4 x+y-2 z) \mathrm{HCO}_{3}^{-}+y \mathrm{NH}_{4}^{+}+z \mathrm{HPO}_{4}{ }^{2-} \\
\mathrm{OM}+4 x \mathrm{Fe}(\mathrm{OH})_{3}+(7 x+y-2 z) \mathrm{CO}_{2} \rightarrow 4 x \mathrm{Fe}^{2+}+(8 x+y-2 z) \mathrm{HCO}_{3}^{-}+y \mathrm{NH}_{4}^{+}+z \mathrm{HPO}_{4}{ }^{2-}+(3 x+y-2 z) \mathrm{H}_{2} \mathrm{O} \\
\mathrm{OM}+0.5 x \mathrm{SO}_{4}{ }^{2-}+(y-2 z) \mathrm{CO}_{2}+(y-2 z) \mathrm{H}_{2} \mathrm{O} \rightarrow 0.5 x \mathrm{H}_{2} \mathrm{~S}+(x+y-2 z) \mathrm{HCO}_{3}{ }^{-}+y \mathrm{NH}_{4}{ }^{+}+z \mathrm{HPO}_{4}{ }^{2-} \\
\mathrm{OM}+(y-2 z) \mathrm{H}_{2} \mathrm{O} \rightarrow 0.5 x \mathrm{CH}_{4}(\mathrm{aq})+(0.5 x-y+2 z) \mathrm{CO}_{2}+(y-2 z) \mathrm{HCO}_{3}^{-}+y \mathrm{NH}_{4}^{+}+z \mathrm{HPO}_{4}{ }^{2-} \\
\mathrm{OM}+(y-2 z) \mathrm{H}_{2} \mathrm{O} \rightarrow 0.5 x \mathrm{CH}_{4}(\mathrm{~g})+(0.5 x-y+2 z) \mathrm{CO}_{2}+(y-2 z) \mathrm{HCO}_{3}^{-}+y \mathrm{NH}_{4}^{+}+z \mathrm{HPO}_{4}{ }^{2-}\end{array}$ & $\begin{array}{l}f_{\mathrm{O}_{2}} k_{\mathrm{OM} 1}[\mathrm{OM} 1] \text { accel } \\
f_{\mathrm{NO}_{3}} k_{\mathrm{OM} 1}[\mathrm{OM} 1] \text { accel } \\
f_{\mathrm{MnO}_{2}} k_{\mathrm{OM} 1}[\mathrm{OM} 1] \\
f_{\mathrm{Fe}(\mathrm{OH})_{3}} k_{\mathrm{OM} 1}[\mathrm{OM} 1] \\
f_{\mathrm{SO}_{4}} k_{\mathrm{OM} 1}[\mathrm{OM} 1] \\
f_{\mathrm{OM}} k_{\mathrm{OM} 1}[\mathrm{OM} 1] f_{\mathrm{m}} \\
f_{\mathrm{OM}} k_{\mathrm{OM} 2}[\mathrm{OM} 2]\left(1-f_{\mathrm{m}}\right)\end{array}$ & $\begin{array}{l}\text { R1, R7 } \\
\text { R2, R8 } \\
\text { R3, R9 } \\
\text { R4, R10 } \\
\text { R5, R11 } \\
\text { R6, R12 } \\
\text { R13 }\end{array}$ \\
\hline $\begin{array}{l}\text { Secondary redox reactions } \\
\mathrm{NH}_{4}^{+} \text {oxidation by } \mathrm{O}_{2} \\
\mathrm{H}_{2} \mathrm{~S} \text { oxidation by } \mathrm{O}_{2} \\
\mathrm{FeS} \text { oxidation by } \mathrm{O}_{2} \\
\mathrm{Mn}^{2+} \text { oxidation by } \mathrm{O}_{2} \\
\mathrm{Fe}^{2+} \text { oxidation by } \mathrm{O}_{2} \\
\mathrm{CH}_{4} \text { oxidation by } \mathrm{O}_{2} \\
\mathrm{Fe}^{2+} \text { oxidation by } \mathrm{Mn}^{2} \text { oxide } \\
\mathrm{CH}_{4} \text { oxidation by } \mathrm{SO}_{4}^{2-} \\
\mathrm{H}_{2} \mathrm{~S} \text { oxidation by } \mathrm{Mn} \text { oxide } \\
\mathrm{H}_{2} \mathrm{~S} \text { oxidation by } \mathrm{Fe} \text { oxide }\end{array}$ & $\begin{array}{l}\mathrm{NH}_{4}^{+}+2 \mathrm{O}_{2}+2 \mathrm{HCO}^{-} \rightarrow \mathrm{NO}_{3}^{-}+2 \mathrm{CO}_{2}+3 \mathrm{H}_{2} \mathrm{O} \\
\mathrm{H}_{2} \mathrm{~S}+2 \mathrm{O}_{2}+2 \mathrm{HCO}_{3}^{-} \rightarrow \mathrm{SO}_{4}^{2-}+2 \mathrm{CO}_{2}+2 \mathrm{H}_{2} \mathrm{O} \\
\mathrm{FeS}+2 \mathrm{O}_{2} \rightarrow \mathrm{SO}_{4}{ }^{2-}+\mathrm{Fe}^{2+} \\
\mathrm{Mn}^{2+}+0.5 \mathrm{O}_{2}+2 \mathrm{HCO}_{3}^{-} \rightarrow \mathrm{MnO}_{2}+2 \mathrm{CO}_{2}+\mathrm{H}_{2} \mathrm{O} \\
\mathrm{Fe}^{2+}+0.25 \mathrm{O}_{2}+2 \mathrm{HCO}_{3}^{-}+1 / 2 \mathrm{H}_{2} \mathrm{O} \rightarrow \mathrm{Fe}(\mathrm{OH})_{3}+2 \mathrm{CO}_{2} \\
\mathrm{CH}_{4}+\mathrm{O}_{2} \rightarrow \mathrm{CO}_{2}+\mathrm{H}_{2} \mathrm{O} \\
2 \mathrm{Fe}^{2+}+\mathrm{MnO}_{2}+2 \mathrm{HCO}_{3}{ }^{-}+2 \mathrm{H}_{2} \mathrm{O} \rightarrow 2 \mathrm{Fe}(\mathrm{OH})_{3}+\mathrm{Mn}^{2+}+2 \mathrm{CO}_{2} \\
\mathrm{CH}_{4}+\mathrm{SO}_{4}{ }^{2-}+\mathrm{CO}_{2} \rightarrow \mathrm{H}_{2} \mathrm{~S}+2 \mathrm{HCO}_{3}^{-} \\
\mathrm{H}_{2} \mathrm{~S}+6 \mathrm{CO}_{2}+4 \mathrm{MnO}_{2}+2 \mathrm{H}_{2} \mathrm{O} \rightarrow 4 \mathrm{Mn}^{2+}+\mathrm{SO}_{4}{ }^{2-}+6 \mathrm{HCO}_{3}^{-} \\
\mathrm{H}_{2} \mathrm{~S}+14 \mathrm{CO}_{2}+8 \mathrm{FeOH}_{3} \rightarrow 8 \mathrm{Fe}^{2+}+\mathrm{SO}_{4}{ }^{2-}+14 \mathrm{HCO}_{3}{ }^{-}+6 \mathrm{H}_{2} \mathrm{O}\end{array}$ & $\begin{array}{l}k_{\text {nh4ox }}\left[\mathrm{NH}_{4}^{+}\right]\left[\mathrm{O}_{2}\right] \\
k_{\text {tsox }}\left[\mathrm{H}_{2} \mathrm{~S}\right]\left[\mathrm{O}_{2}\right] \\
k_{\text {fesox }}[\mathrm{FeS}]\left[\mathrm{O}_{2}\right] \\
k_{\text {mnox }}\left[\mathrm{Mn}^{2+}\right]\left[\mathrm{O}_{2}\right] \\
k_{\text {feox }}\left[\mathrm{Fe}^{2+}\right]\left[\mathrm{O}_{2}\right] \\
k_{\text {ch4ox }}\left[\mathrm{CH}_{4}\right]\left[\mathrm{O}_{2}\right] \\
k_{\text {femn }}\left[\mathrm{Fe}^{2+}\right]\left[\mathrm{MnO}_{2}\right] \\
k_{\text {ch4so4 }}\left[\mathrm{CH}_{4}\right]\left[\mathrm{SO}_{4}{ }^{2-}\right] \\
k_{\text {tsmn }}\left[\mathrm{H}_{2} \mathrm{~S}\right]\left[\mathrm{MnO} \mathrm{Mn}_{2}\right] \\
k_{\text {tsfe }}\left[\mathrm{H}_{2} \mathrm{~S}\right]\left[\mathrm{Fe}(\mathrm{OH})_{3}\right]\end{array}$ & $\begin{array}{l}\text { R14 } \\
\text { R15 } \\
\text { R16 } \\
\text { R17 } \\
\text { R18 } \\
\text { R19 } \\
\text { R20 } \\
\text { R21 } \\
\text { R22, R23 } \\
\text { R24, R25 }\end{array}$ \\
\hline $\begin{array}{l}\text { Adsorption and equilibrium rec } \\
\mathrm{NH}_{4}^{+} \text {adsorption } \\
\text { Carbonate equilibria } \\
\text { Sulfide equilibrium }\end{array}$ & $\begin{array}{l}\text { ons } \\
\mathrm{NH}_{4}^{+} \leftrightarrow \mathrm{NH}_{4}^{+} \text {ads } \\
\mathrm{H}^{+}+\mathrm{HCO}_{3}{ }^{-} \leftrightarrow \mathrm{CO}_{2}+\mathrm{H}_{2} \mathrm{O} \\
\mathrm{CO}_{3}{ }^{2-}+\mathrm{H}^{+} \leftrightarrow \mathrm{HCO}_{3}^{-} \\
\mathrm{H}^{+}+\mathrm{HS}^{-} \leftrightarrow \mathrm{H}_{2} \mathrm{~S}\end{array}$ & $\begin{array}{l}K_{\mathrm{N}}\left[\mathrm{NH}_{4}^{+}\right] \\
\text {Keqc1 } \\
\text { Keqc2 } \\
\text { Keqs }\end{array}$ & $\begin{array}{l}\text { R26 } \\
\text { R27 } \\
\text { R28 } \\
\text { R29 }\end{array}$ \\
\hline $\begin{array}{l}\text { Precipitation and dissolution } r \\
\text { FeS dissolution }{ }^{\mathrm{f}} \\
\text { FeS precipitation } \\
\text { Pyrite precipitation }\end{array}$ & $\begin{array}{l}\text { tions (non-redox) } \\
\mathrm{FeS}+2 \mathrm{H}^{+} \rightarrow \mathrm{Fe}^{2+}+\mathrm{H}_{2} \mathrm{~S} \\
\mathrm{Fe}^{2+}+\mathrm{H}_{2} \mathrm{~S} \rightarrow \mathrm{FeS}+2 \mathrm{H}^{+} \\
\mathrm{FeS}+\mathrm{H}_{2} \mathrm{~S} \rightarrow \mathrm{FeS}_{2}+\mathrm{H}_{2}\end{array}$ & $\begin{array}{l}\text { kfesdis }[\mathrm{FeS}](1-\Omega \mathrm{FeS}) \\
\text { kfespre }(\Omega \mathrm{FeS}-1) \\
\text { Kpyrpre }[\mathrm{FeS}]\left[\mathrm{H}_{2} \mathrm{~S}\right]\end{array}$ & $\begin{array}{l}\text { R30 } \\
\text { R31 } \\
\text { R32 }\end{array}$ \\
\hline
\end{tabular}

Reaction parameters are defined in Table 3.

${ }^{\mathrm{a}} \mathrm{OM}=\left(\mathrm{CH}_{2} \mathrm{O}\right)_{x}\left(\mathrm{NH}_{3}\right)_{y}\left(\mathrm{H}_{3} \mathrm{PO}_{4}\right)_{z}$, where $x, y, z$ represent the CNP ratios given in Table 3 .

${ }^{\mathrm{b}}$ For reactions R1-R6 $k_{\mathrm{OM} 1}$ and $\mathrm{CNP} \mathrm{OM}_{1}$ are used, for R7-R13 $k_{\mathrm{OM} 2}$ and $\mathrm{CNP}_{\mathrm{OM} 2}$ are used; the $f_{\mathrm{TEA}}$ terms are the fractions of total carbon mineralization assigned to the different TEA pathways.

c The accel term is only used in R1 and R2.

d The term $f_{\mathrm{m}}$ is defined by Eq. (1), and controls the switching between $\mathrm{R} 12$ and $\mathrm{R} 13, f_{\mathrm{m}}$ is not included in R6 which does not produce methane in excess of saturation in this system.

${ }^{\mathrm{e}} \mathrm{R} 23$ with $\mathrm{MnO}_{2} \mathrm{~B}, \mathrm{R} 25$ with $\mathrm{Fe}(\mathrm{OH})_{3} \mathrm{~B}$

${ }^{\mathrm{f}} \Omega \mathrm{FeS}=\mathrm{Fe}^{2+} \mathrm{H}_{2} \mathrm{~S} /\left(\mathrm{H}^{+}\right)^{2} \mathrm{Kfes}, \mathrm{R} 30=0$ when $\Omega \mathrm{FeS}>1$.

${ }^{\mathrm{g}} \mathrm{R} 31=0$ when $\Omega \mathrm{FeS}<1$. 
Table 3

Reaction parameter values used in the model

\begin{tabular}{|c|c|c|c|c|c|}
\hline Parameter & Value & Unit & Source & Ref. & Description \\
\hline \multicolumn{6}{|c|}{ Primary redox reactions } \\
\hline$k_{\mathrm{OM} 1}$ & 1 & $\mathrm{yr}^{-1}$ & $\mathrm{C}, \mathrm{M}$ & & Degradation rate constant OM1 \\
\hline$k_{\mathrm{OM} 2}$ & 0.01 & $\mathrm{yr}^{-1}$ & $\mathrm{C}, \mathrm{M}$ & & Degradation rate constant $\mathrm{OM} 2$ \\
\hline$k_{\mathrm{OM} 3}$ & 0 & $\mathrm{yr}^{-1}$ & $\mathrm{M}$ & & OM3 not reactive \\
\hline accel & 25 & - & $\mathrm{M}, \mathrm{C}$ & & Acceleration factor: $\mathrm{R} 1-\mathrm{R} 2$ \\
\hline$f_{\mathrm{TEA}}$ & $0-1$ & - & $\mathrm{M}$ & & Fraction of total OM degradation by each TEA pathway \\
\hline $\mathrm{CNP}_{\mathrm{OM} 1}$ & $112: 20: 1$ & - & $\mathrm{C}, \mathrm{L}$ & 1 & CNP for OM1 (highly reactive) \\
\hline $\mathrm{CNP}_{\mathrm{OM} 2}$ & 200:20:1 & - & $\mathrm{C}$ & & CNP for OM2 (less reactive) \\
\hline$K_{\mathrm{m}} \mathrm{O}_{2}$ & 8 & $\mu \mathrm{M}$ & $\mathrm{L}$ & 2 & Limitation for oxic respiration \\
\hline$K_{\mathrm{m}} \mathrm{NO}_{3}^{-}$ & 10 & $\mu \mathrm{M}$ & $\mathrm{L}$ & 2 & Limitation for denitrification \\
\hline$K_{\mathrm{m}} \mathrm{MnO}_{2}$ & 16 & $\mu \mathrm{mol} \mathrm{g} \mathrm{g}^{-1}$ & $\mathrm{~L}$ & 3 & Limitation for $\mathrm{Mn}$ reduction \\
\hline$K_{\mathrm{m}} \mathrm{FeOH}_{3}$ & 200 & $\mu \mathrm{mol} \mathrm{g}^{-1}$ & M & & Limitation for Fe reduction \\
\hline $\mathrm{K}_{\mathrm{m}} \mathrm{SO}_{4}^{2-}$ & 100 & $\mu \mathrm{M}$ & $\mathrm{C}, \mathrm{L}$ & 2 & Limitation for $\mathrm{SO}_{4}{ }^{2-}$ reduction \\
\hline $\mathrm{CH}_{4}{ }^{*}$ & 2.66 & $\mathrm{mM}$ & I & & Saturation conc. at study site \\
\hline$f_{\mathrm{m}}$ & $0-1$ & - & M & 4 & Methane switch (see Eq. (1)) \\
\hline$S_{\mathrm{m}}$ & 3.0 & $\mathrm{mM}^{-1}$ & $\mathrm{M}, \mathrm{L}$ & 4 & Methane switch (see Eq. (1)) \\
\hline \multicolumn{3}{|c|}{ Secondary redox reaction } & \multicolumn{3}{|c|}{ Range from $(2,3,5,6)$} \\
\hline knh4ox & $2 \times 10^{1}$ & $\mu \mathrm{M}^{-1} \mathrm{yr}^{-1}$ & \multicolumn{2}{|c|}{$5-7.9 \times 10^{1}$} & R14, nitrification \\
\hline ktsox & $1 \times 10^{3}$ & $\mu \mathrm{M}^{-1} \mathrm{yr}^{-1}$ & \multicolumn{2}{|c|}{$1.6 \times 10^{-1}-1.6 \times 10^{3}$} & $\mathrm{R} 15$, sulfide oxidation by $\mathrm{O}_{2}$ \\
\hline kfesox & $2 \times 10^{1}$ & $\mu \mathrm{M}^{-1} \mathrm{yr}^{-1}$ & \multicolumn{2}{|c|}{$1.9 \times 10^{-1}-2 \times 10^{1}$} & $\mathrm{R} 16, \mathrm{FeS}$ oxidation by $\mathrm{O}_{2}$ \\
\hline kmnox & 1.0 & $\mu \mathrm{M}^{-1} \mathrm{yr}^{-1}$ & \multicolumn{2}{|c|}{$3.5 \times 10^{-1}-2 \times 10^{3}$} & $\mathrm{R} 17, \mathrm{Mn}^{2+}$ oxidation by $\mathrm{O}_{2}$ \\
\hline kfeox & $5 \times 10^{1}$ & $\mu \mathrm{M}^{-1} \mathrm{yr}^{-1}$ & \multicolumn{2}{|c|}{$3.5 \times 10^{-1}-1.6 \times 10^{4}$} & $\mathrm{R} 18, \mathrm{Fe}^{2+}$ oxidation by $\mathrm{O}_{2}$ \\
\hline kch4ox & $1 \times 10^{4}$ & $\mu \mathrm{M}^{-1} \mathrm{yr}^{-1}$ & \multicolumn{2}{|c|}{$1 \times 10^{4}$} & $\mathrm{R} 19$, methane oxidation by $\mathrm{O}_{2}$ \\
\hline kfemn & $1 \times 10^{-1}$ & $\mu \mathrm{M}^{-1} \mathrm{yr}^{-1}$ & \multicolumn{2}{|c|}{$2.4 \times 10^{-3}-3$} & $\mathrm{R} 20, \mathrm{Fe}^{2+}$ oxidation by Mn-oxides \\
\hline $\mathrm{kch} 4 \mathrm{so} 4$ & $1 \times 10^{-4}$ & $\mu \mathrm{M}^{-1} \mathrm{yr}^{-1}$ & \multicolumn{2}{|c|}{$1 \times 10^{-2}-1 \times 10^{4}$} & $\mathrm{R} 21$, methane oxidation by $\mathrm{SO}_{4}^{2-}$ \\
\hline ktsmn & $7.5 \times 10^{-3}$ & $\mu \mathrm{M}^{-1} \mathrm{yr}^{-1}$ & \multicolumn{2}{|c|}{$1 \times 10^{-2}-6.3 \times 10^{-1}$} & R22, R23 sulfide oxidation by Mn-oxides \\
\hline ktsfe & $2.5 \times 10^{-3}$ & $\mu \mathrm{M}^{-1} \mathrm{yr}^{-1}$ & \multicolumn{2}{|c|}{$8 \times 10^{-3}-9.5 \times 10^{-2}$} & R24, R25 sulfide oxidation by Fe-oxides, see also (7) \\
\hline \multicolumn{6}{|c|}{ Adsorption, equilibrium, dissolution, and precipitation constants } \\
\hline$K_{\mathrm{N}}$ & 1.4 & - & $\mathrm{L}$ & 3 & Ammonium adsorption constant \\
\hline Keqc1 & $3.0 \times 10^{-7}$ & - & $\mathrm{I}$ & 8 & Carbonate equilibrium constant \\
\hline Keqc2 & $3.6 \times 10^{-13}$ & - & I & 8 & Bicarbonate equilibrium constant \\
\hline Keqs & $6.3 \times 10^{-8}$ & - & I & 9 & Sulfide equilibrium constant \\
\hline Kfes & $9.6 \times 10^{3}$ & - & $\mathrm{L}$ & 10 & FeS stability constant \\
\hline kfespre & $1.5 \times 10^{-3}$ & $\mathrm{~mol} \mathrm{~g}^{-1} \mathrm{yr}^{-1}$ & M & & FeS Precipitation rate constant \\
\hline kfesdis & $1.0 \times 10^{-3}$ & $\mathrm{yr}^{-1}$ & $\mathrm{~L}$ & 3 & FeS dissolution rate constant \\
\hline Kpyrpre & $3.3 \times 10^{-3}$ & $\mu \mathrm{M}^{-1} \mathrm{yr}^{-1}$ & $\mathrm{~L}$ & 11 & $\mathrm{FeS}_{2}$ precipitation rate constant \\
\hline
\end{tabular}

The source of the parameter values are indicated by the following code: C, constrained from experimental data; M, derived by model fitting; I, independently determined from field data; L, literature value, with references given at the bottom of the table. A range of literature values for the secondary reaction rate constants is provided.

Ref.: 1. Koelmans (1998); 2. Van Cappellen and Wang (1995); 3. Van Cappellen and Wang (1996); 4. Martens et al. (1998); 5. Berg et al. (2003); 6. Fossing et al. (2004); 7. Poulton et al. (2004); 8. Cai and Wang (1998); 9. Pilson (1998); 10. Davison et al. (1999); 11. Rickard (1997).

The rates of $\mathrm{FeS}$ dissolution and precipitation (R30-R31, Table 2) are dependent on the degree of FeS under- or supersaturation of the pore water, using the formulations of Van Cappellen and Wang (1996). Formation of pyrite $\left(\mathrm{FeS}_{2}\right)$ is described as a reaction of $\mathrm{FeS}$ and $\mathrm{H}_{2} \mathrm{~S}$, using the bimolecular rate equation of Rickard (1997). Dissolution of pyrite is not included in the model.

Adsorption of $\mathrm{NH}_{4}^{+}$to cation exchange sites is represented by a linear equilibrium isotherm, with a constant adsorption coefficient, $K_{\mathrm{N}}$. The model further includes homogenous carbonate and sulfide equilibrium reactions (R27-R29), which are assumed to be the major aqueous $\mathrm{pH}$ buffers in this system. The concentration of $\mathrm{H}^{+}$is explicitly computed from the equilibrium conditions (Jourabchi et al., 2005). Reactions with sulfide are written with $\mathrm{H}_{2} \mathrm{~S}$ as the reactive species, however the inclusion of the $\mathrm{H}_{2} \mathrm{~S}$ dissociation equilibrium
(R29) means that both $\mathrm{H}_{2} \mathrm{~S}$ and $\mathrm{HS}^{-}$species concentrations respond to sulfide producing and consuming reactions.

\subsection{Transport}

Solute transport processes included are molecular diffusion, bioirrigation, bioturbation, and sediment advection, while solid species are transported by bioturbation and sediment advection. Molecular diffusion coefficients at $0{ }^{\circ} \mathrm{C}$ and temperature correction factors are taken from Van Cappellen and Wang (1995), and references therein, and corrected for tortuosity effects after Boudreau (1996). Porosity, $\varphi\left(\mathrm{cm}^{3} \mathrm{~cm}^{-3}\right)$, varies with depth as defined by the equation given in Table 4 and shown in Fig. 2. The advection velocity accounts for the variations in porosity (Berner, 1980). 
Table 4

Depth distributions and parameter values for physical properties and transport processes

\begin{tabular}{|c|c|c|c|c|}
\hline Depth distributions & & & & Description \\
\hline$\varphi(x)=\varphi_{\infty}+\left(\varphi_{0}-\varphi_{\infty}\right) \mathrm{e}^{-(\tau x)}$ & & & & Porosity distribution (Fig. 2) \\
\hline$\alpha=\left\{\begin{array}{l}\alpha_{0}\left(1-\mathrm{e}^{(x-17)}\right)(x \leqslant 17 \mathrm{~cm}) \\
0(x>17 \mathrm{~cm})\end{array}\right.$ & & & & Distribution of bioirrigation coefficient $\alpha$ (Fig. 3) \\
\hline$D_{\mathrm{b}}=D_{\mathrm{b}}(0) \mathrm{e}^{-(x / \lambda)}$ & & & & Distribution of bioturbation coefficient $D_{\mathrm{b}}$ (Fig. 4) \\
\hline \multicolumn{5}{|l|}{ Parameter definitions and values } \\
\hline Parameter & Value & Unit & Source & Description \\
\hline$\varphi_{0}$ & 0.89 & $\mathrm{~cm}^{3} \mathrm{~cm}^{-3}$ & Measured & Porosity at SWI \\
\hline$\varphi_{\infty}$ & 0.79 & $\mathrm{~cm}^{3} \mathrm{~cm}^{-3}$ & Measured & Porosity at infinite depth \\
\hline$\tau$ & 0.2 & $\mathrm{~cm}^{-1}$ & Data fitting & Porosity attenuation \\
\hline$x$ & $0-30$ & $\mathrm{~cm}$ & Measured & Sediment depth \\
\hline$\omega$ & 1.0 & $\mathrm{~cm} \mathrm{yr}^{-1}$ & Literature $^{\mathrm{a}}$ & Sediment accumulation rate at SWI \\
\hline$\alpha$ & $0-10$ & $\mathrm{yr}^{-1}$ & Data fitting & Bioirrigation coefficient \\
\hline$\alpha_{0}$ & 10 & $\mathrm{yr}^{-1}$ & Data fitting & Value of $\alpha$ at SWI \\
\hline$D_{\mathrm{b}}$ & $0-5$ & $\mathrm{~cm}^{2} \mathrm{yr}^{-1}$ & Data fitting & Bioturbation coefficient \\
\hline$D_{\mathrm{b}} 0$ & 5 & $\mathrm{~cm}^{2} \mathrm{yr}^{-1}$ & Data fitting & Value of $D_{\mathrm{b}}$ at SWI \\
\hline$\lambda$ & 2.5 & $\mathrm{~cm}$ & Data fitting & $D_{\mathrm{b}}$ attenuation \\
\hline$\rho$ & 2.1 & $\mathrm{~g} \mathrm{~cm}^{-3}$ & Measured & Sediment density \\
\hline Temperature & 12 & ${ }^{\circ} \mathrm{C}$ & Measured & Mean sediment temperature \\
\hline
\end{tabular}

${ }^{\text {a }}$ van Wijngaarden et al. (2002).

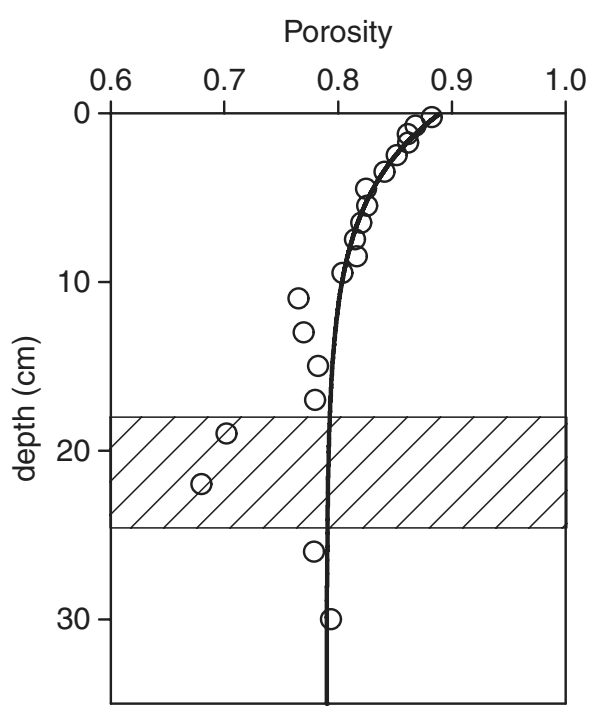

Fig. 2. Depth distribution of sediment porosity in late-summer. The solid line is the exponential fit used to represent porosity in the model (see equation in Table 4). The shaded area between approximately 18 and $24 \mathrm{~cm}$ depth denotes a zone of coarser-grained sediment.

The pore water profiles of many species, including the conservative ions $\mathrm{Na}^{+}$and $\mathrm{Cl}^{-}$, show evidence of bioirrigation (Fig. 3). As can be seen in Fig. 3, the concentrations of $\mathrm{Na}^{+}$and $\mathrm{Cl}^{-}$increase with depth below $17 \mathrm{~cm}$. It is unlikely that these concentration profiles reflect the ongoing replacement of remnant saline pore waters by freshwater. The age of the lake (created in 1970) and the sedimentation rate $\left(\sim 1 \mathrm{~cm} \mathrm{yr}^{-1}\right.$, see below), imply that the sediment in the upper $30 \mathrm{~cm}$ was deposited in freshwater conditions. The increasing salinity in the lower half of the cores thus indicates salt diffusion from a deeper source, probably related to subterranean seawater intrusion. The near-constant concentrations of $\mathrm{Na}^{+}$and $\mathrm{Cl}^{-}$in the upper $17 \mathrm{~cm}$ then require enhanced pore water transport to counteract the upward salt diffusion. This enhanced pore water transport is attributed to bioirrigation.

The depth distribution of the bioirrigation coefficient $\alpha$ (Table 4) was derived by fitting the $\mathrm{Na}^{+}$and $\mathrm{Cl}^{-}$profiles to the steady state diffusion-irrigation equation, with the concentrations at the SWI and at $30 \mathrm{~cm}$ depth fixed to the measured values. Note that this approach yields a minimum estimate of the irrigation intensity. The selected form of the depth distribution (Fig. 3c, Table 4) produced a better fit to the pore water $\mathrm{Na}^{+}$and $\mathrm{Cl}^{-}$profiles than a linearly or exponentially attenuating bioirrigation coefficient distribution. It is also preferred over the simpler step-function distribution, as it avoids a sharp discontinuity of $\alpha$ at the bottom of the irrigated zone. The value of $\alpha_{0}$ obtained $\left(10 \mathrm{yr}^{-1}\right)$ is similar to irrigation coefficients reported for freshwater sediment microcosms inhabited by deposit feeding tubificid worms (5-10 $\mathrm{yr}^{-1}$, Wang and Matisoff, 1997), at comparable population densities as those found by Smit et al. (1995) in fine-grained Haringvliet Lake sediments (in the order of $10^{3}$ organisms $\mathrm{m}^{-2}$ ).

All solutes are assigned the bioirrigation coefficient distribution shown in Table 4, except $\mathrm{Mn}^{2+}$ and $\mathrm{Fe}^{2+}$. Net vertical transport of $\mathrm{Mn}^{2+}$ and $\mathrm{Fe}^{2+}$ by irrigation is strongly impeded, because these pore water species oxidatively precipitate near flushed burrow walls, and are therefore prevented from escaping via the burrows (Berg et al., 2003; Meile et al., 2005). The value of $\alpha$ for $\mathrm{Fe}^{2+}$ is reduced by $100 \%$ (no bioirrigation) while $\alpha$ for $\mathrm{Mn}^{2+}$ is reduced by $40 \%$. The reduced $\alpha$ values produce modeled pore water profiles that are consistent with the data. The variable adjustments to the irrigation coefficients of $\mathrm{Mn}^{2+}$ and $\mathrm{Fe}^{2+}$ are also in agreement with Berg et al. (2003) who found that, in contrast to $\mathrm{Fe}^{2+}$, pore water distributions 

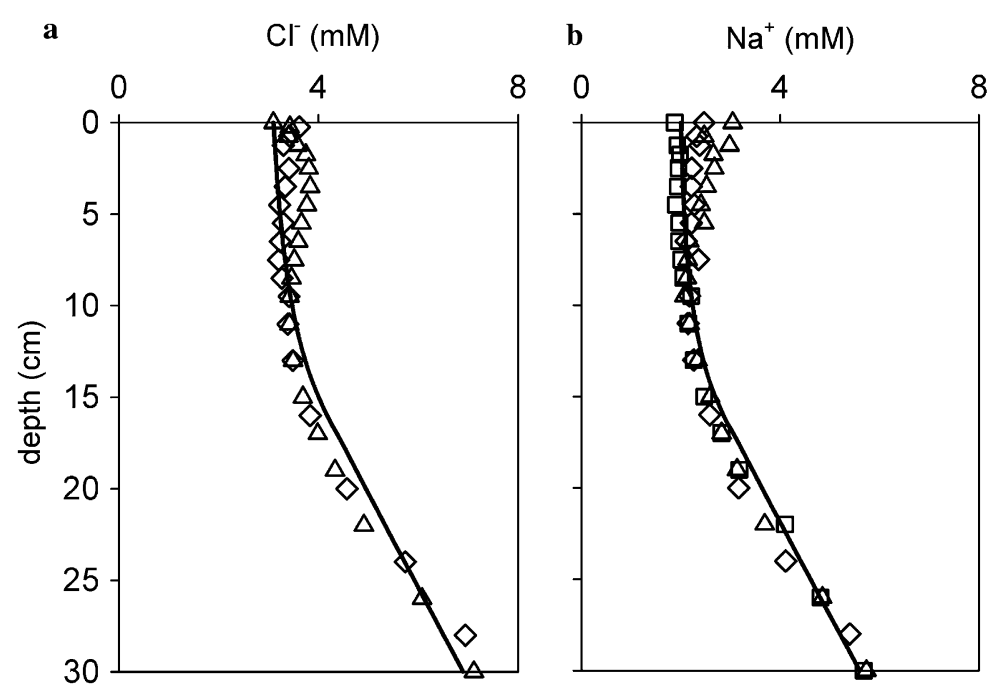

$$
\text { c } \quad \alpha\left(\mathrm{yr}^{-1}\right)
$$

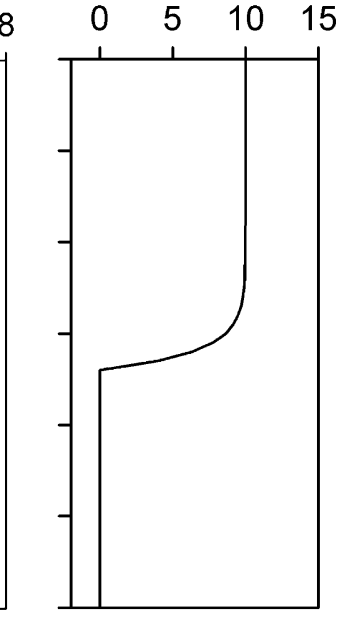

Fig. 3. Pore water profiles of $\mathrm{Cl}^{-}$in (a) fall $(\diamond)$ and spring $(\triangle)$, and $\mathrm{Na}^{+}$in (b) fall $(\diamond)$, late-summer $(\square)$ and spring $(\triangle)$. The solid lines represent a model fit for fixed boundary concentrations (at 0 and $30 \mathrm{~cm}$ ), and the bioirrigation distribution given in Table 4 . The depth distribution of the irrigation coefficient $\alpha$ is depicted in panel (c).

of $\mathrm{Mn}^{2+}$ show evidence of transport by irrigation, most likely because of slower oxidation rates compared to $\mathrm{Fe}^{2+}$.

Particle mixing is represented as a diffusion process (Berner, 1980). It results mainly from the activity of benthic macrofauna (bioturbation), although some effect of sediment resuspension cannot be excluded at the shallow water depth of the sampling site $(7.5 \mathrm{~m})$. The bioturbation coefficient, $D_{\mathrm{b}}\left(\mathrm{cm}^{2} \mathrm{yr}^{-1}\right)$ is defined by an exponentially decaying depth distribution (Table 4; Wijsman et al., 2002). The magnitude and depth distribution of the biodiffusion coefficient were constrained by fitting the measured profiles of Pheo- $a$, a breakdown product of Chl- $a$ (Fig. 4). Sediment profiles of Chl- $a$ have been previously used to quantify sediment mixing (e.g. Sun et al., 1994; Boon and Duineveld,

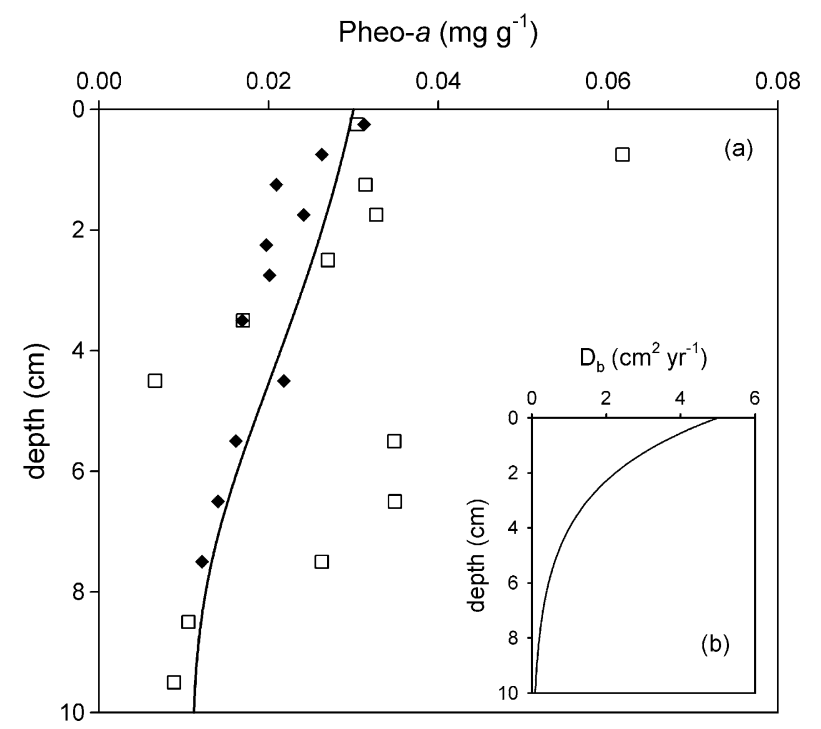

Fig. 4. Pheo- $a$ sediment profiles for fall $(\bullet)$ and late-summer ( $\square)$. The solid line in (a) is the modeled fall Pheo- $a$ distribution obtained using the $D_{\mathrm{b}}$ depth distribution depicted in the inset (b). The $D_{\mathrm{b}}$ depth distribution is given in Table 4.
1998; Wijsman et al., 2002). The depth distribution of $D_{\mathrm{b}}$ was obtained assuming steady state and a degradation rate constant of $0.05 \mathrm{yr}^{-1}$ for Pheo- $a$ (Table 4, Fig. 4b). A major source of uncertainty in this estimation is the value of the degradation rate constant imposed in the calculations. For refractory Pheo- $a$ in marine sediments the reported values exhibit a considerable range, from 0.002 to $0.15 \mathrm{yr}^{-1}$ (Stephens et al., 1997). Bioturbation is described as a diffusion process for the sake of simplicity; however, actual sediment mixing processes may be more complex as evidenced by the pigment data from late-summer (Fig. 4) which suggests non-local sediment transport.

\subsection{Boundary conditions}

Upper boundary conditions for solutes and solids at the SWI are summarized in Table 1. All chemical species are assigned a zero concentration gradient as lower boundary condition. The model depth $(100 \mathrm{~cm})$ extends well below the depth interval examined in this study $(0-30 \mathrm{~cm})$, to minimize computational artifacts associated with the lower boundary conditions.

In the absence of direct measurements, initial estimates of particulate depositional fluxes were derived from suspended matter concentrations and the sedimentation rate. The latter was estimated at $1 \mathrm{~cm} \mathrm{yr}^{-1}$, based on the radiometric age determinations of van Wijngaarden et al. (2002). The initial flux estimates were then adjusted by trial and error to fit measured concentration profiles. The deposition fluxes of $\mathrm{Mn}$ and $\mathrm{Fe}$ oxides were adjusted to optimize the simultaneous fit of the concentration distributions of both solid-phase and pore water $\mathrm{Mn}$ and Fe. The model-calculated pore water $\mathrm{O}_{2}$ distribution is particularly sensitive to the deposition flux of the most reactive organic matter, OM1. Hence, the measured $\mathrm{O}_{2}$ microprofiles were used primarily to constrain the flux of OM1. The pore water 
profiles of $\mathrm{NH}_{4}^{+}$and DIC were used in a similar manner to determine the flux of OM2. Once the fluxes of OM1 and OM2 were fixed, the flux of non-reactive organic matter, OM3, was adjusted to reproduce the measured total organic carbon concentrations.

\section{Results}

Sediment porosity approached $90 \%$ at the SWI, and decreased near-exponentially with depth to values of around $80 \%$ (Fig. 2). The anomalously low porosities in depth interval $18-24 \mathrm{~cm}$ corresponded to an increase in sediment grain size (not shown). This change in sediment grain size may be the result of lake shore erosion. Concentrations of $\mathrm{C}_{\mathrm{org}}$, total $\mathrm{Fe}$, and total $\mathrm{Mn}$ were also lower in the $18-24 \mathrm{~cm}$ depth range due to dilution by coarser grained sediment (Figs. 5 and 6).

The particulate $\mathrm{C}_{\text {org }}$ concentration profile shows little change with depth in the upper $18 \mathrm{~cm}$ of sediment, suggesting that the major part of organic matter is refractory (Fig. 5). The profiles of total Mn and Fe do not exhibit distinct changes with depth. However, the concentrations of easily reducible $\mathrm{Mn}_{\text {asc }}$ and $\mathrm{Fe}_{\text {asc }}$ pools were highest near the SWI and declined with depth (Fig. 6). Reactive $\mathrm{Mn}_{\text {asc }}$ represented approximately $45 \%$ of the total Mn concentration near the SWI, while $\mathrm{Fe}_{\text {asc }}$ represented less than $20 \%$ of total Fe near the SWI. AVS concentrations were lower in spring than in late-summer in depth interval $4-15 \mathrm{~cm}$. In late-summer, AVS accounted for $22-48 \%$ of the total sulfur measured below $4 \mathrm{~cm}$ depth (Fig. 7).

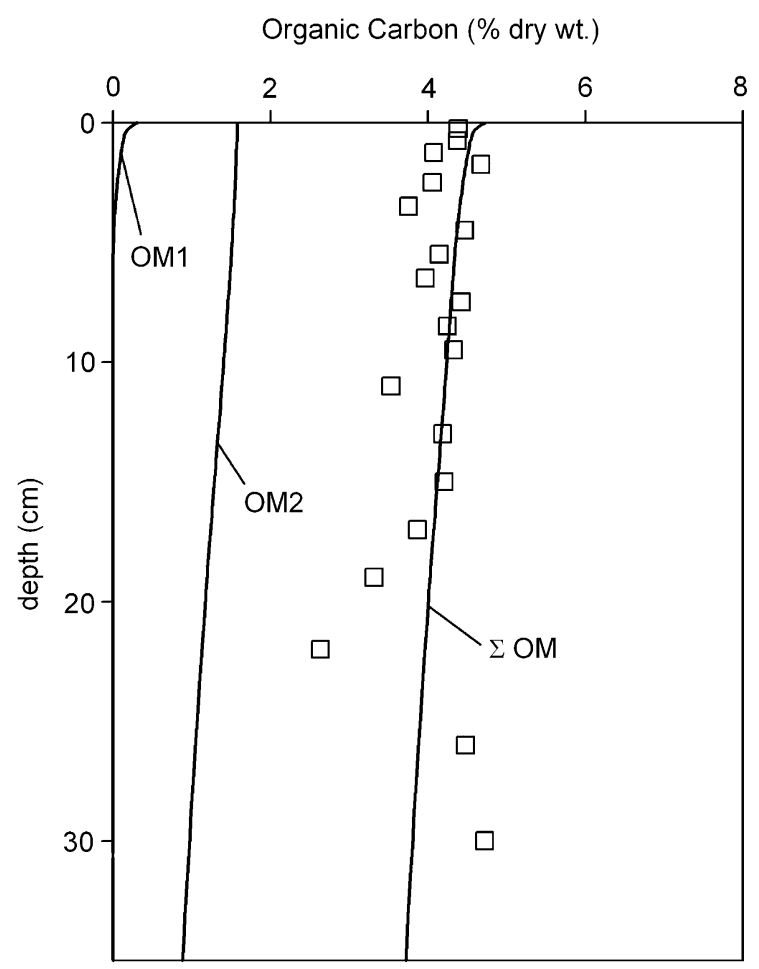

Fig. 5. Depth distribution of the measured total organic carbon ( $\square$ ), and model distributions of the reactive organic carbon pools OM1, OM2, and the sum of the three OM pools ( $\Sigma \mathrm{OM})$ (solid lines).
Pore water $\mathrm{O}_{2}$ and $\mathrm{NO}_{3}^{-}$were depleted within the uppermost centimeter of sediment (Fig. 8), implying high rates of oxygen and nitrate reduction. Dissolved Mn concentrations exhibited a subsurface peak at approximately $3 \mathrm{~cm}$. The peak in dissolved $\mathrm{Mn}$ concentrations was greater in spring than at the other two sampling dates. The concentrations of dissolved $\mathrm{Fe}$ were fairly constant in the upper $13 \mathrm{~cm}$ and then increased steadily with depth. Measurable pore water concentrations of sulfate persisted down to $20 \mathrm{~cm}$ depth in fall. In spring and late-summer, the penetration depth of $\mathrm{SO}_{4}{ }^{2-}$ was shallower, although in late-summer concentrations of approximately $60 \mu \mathrm{M}$ were measured between 5 and $17 \mathrm{~cm}$ depth. Colorimetric sulfide analysis of centrifuged pore water never resulted in detectable concentrations. The sulfide pore water profile obtained with the AgI DGT probe gave S(-II) concentrations in the range of $5-10 \mu \mathrm{M}$ in the $2-10 \mathrm{~cm}$ depth interval. Concentrations of $\mathrm{NH}_{4}^{+}$and alkalinity increased with depth, providing evidence that $\mathrm{C}_{\text {org }}$ mineralization occurred at least down to $30 \mathrm{~cm}$. Pore water $\mathrm{pH}$ was most variable in the upper $10 \mathrm{~cm}$ of sediment; below this depth $\mathrm{pH}$ values displayed a gradually decreasing trend with depth.

Experimentally determined rates of carbon mineralization in oxic slurries were systematically higher than those of anoxic slurries (Table 5). The average rate of $\mathrm{CO}_{2}$ production observed in anoxic slurries was 17 times less than that found in oxic slurries. Potential rates of denitrification were approximately 34 times greater than potential rates of sulfate reduction measured with FTRs from the upper $4 \mathrm{~cm}$ of sediment. All methods yielded rates that varied with the sampling date, and depth, but also between duplicates. Despite the observed variability (Table 5), the data implied that aerobic respiration and denitrification produced much higher rates of carbon mineralization than other, anoxic degradation pathways.

\section{Discussion}

A fully transient simulation of the seasonal variations in sediment biogeochemistry proved unfeasible, primarily because the temporal evolution of the boundary conditions at the SWI could not be accurately constrained. This particularly holds for the input fluxes of reactive organic matter (OM1, OM2) and reactive Fe and Mn phases. In addition, with the notable exceptions of $\mathrm{Mn}^{2+}$ and $\mathrm{SO}_{4}{ }^{2-}$, the overall trends of the pore water profiles did not vary greatly among the sampling times (Fig. 8). Therefore, we opted for a modeling strategy aimed at reproducing the general features of the solid-phase and pore water distributions.

The solid curves in Figs. 5-8 represent the output of a steady-state solution of the model fitted to match the entire set of chemical data collected. As can be seen, the model is able to simultaneously reproduce the majority of observed trends in the concentration profiles. It is important to note that in the model calculations, the transport rates are obtained independently from the fitted data set in Figs. 5-8 (Section 4.2). Taken together, the model appears to provide a reasonable, 

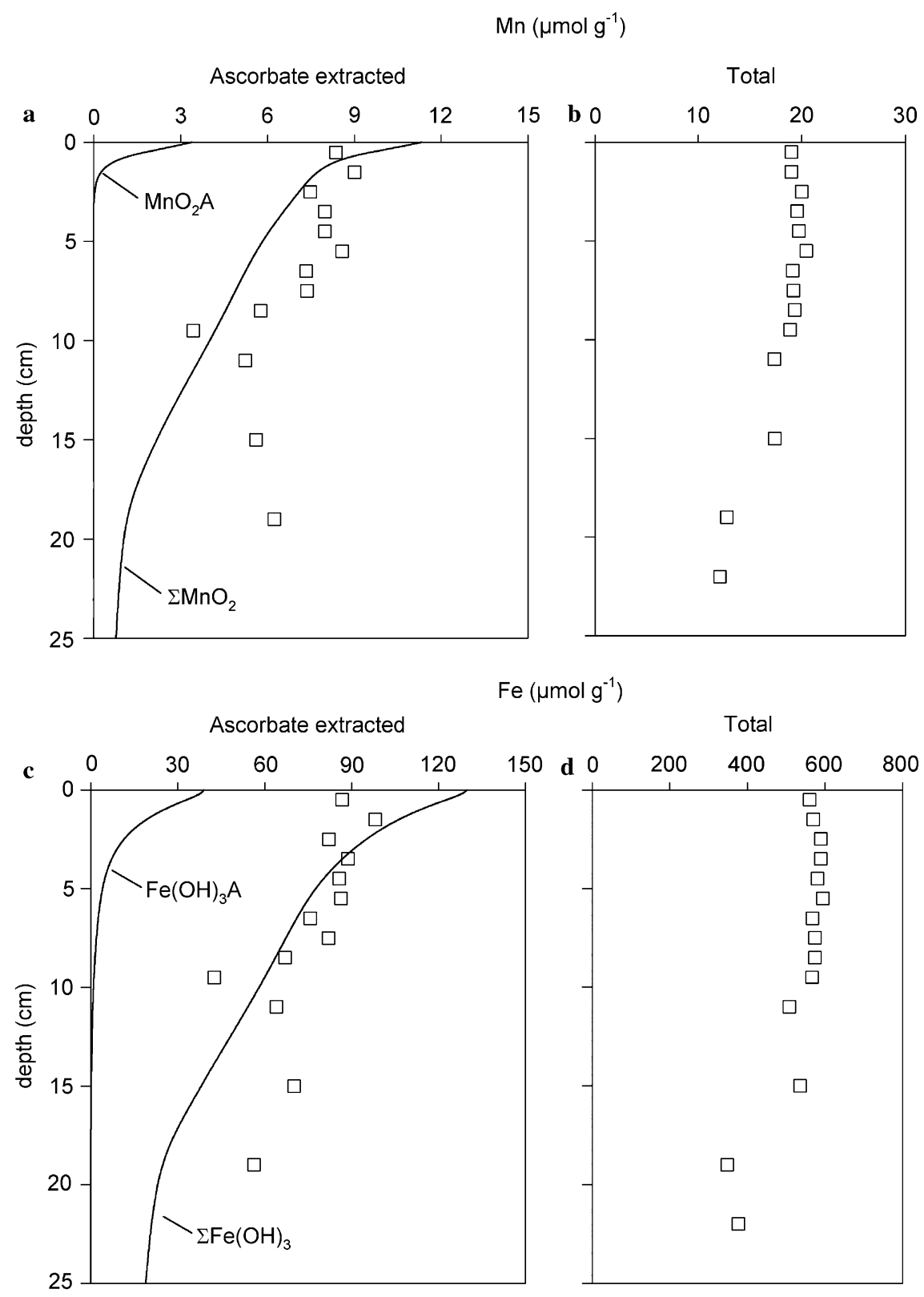

Fig. 6. Depth distributions of reducible Mn (a), total Mn (b), reducible Fe (c), and total Fe (d). Reducible Mn and Fe are obtained by chemical extraction with ascorbate at near-neutral $\mathrm{pH}$. This method releases the reactive fractions of oxidized $\mathrm{Mn}$ and Fe (Hyacinthe and Van Cappellen, 2004). Also shown are the model distributions of $\mathrm{MnO}_{2} \mathrm{~A}, \mathrm{MnO}_{2} \mathrm{~A}+\mathrm{MnO}_{2} \mathrm{~B}\left(\Sigma \mathrm{MnO}_{2}\right), \mathrm{Fe}(\mathrm{OH})_{3} \mathrm{~A}$, and $\mathrm{Fe}(\mathrm{OH})_{3} \mathrm{~A}+\mathrm{Fe}(\mathrm{OH})_{3} \mathrm{~B}\left(\Sigma \mathrm{Fe}(\mathrm{OH})_{3}\right)$. Model distributions are depicted as solid lines, extraction data are indicated with $(\square)$ symbols.

time-averaged representation of the important biogeochemical processes taking place in the sediment.

Discrepancies between model calculated and measured concentration profiles may arise from the fact that the system is not at steady state. Especially for the solid-phase constituents (Figs. 5-7), some of the variability in the concentrations reflects historical fluctuations in deposition fluxes. Discrepancies may also result from processes that are not included in the reaction network of the model. For example, the model systematically under-predicts pore water $\mathrm{pH}$ and alkalinity at depth in the sediment (Fig. 8). This can be explained by additional buffering by carbonate mineral dissolution, a process which is not included in the model version used here (Jourabchi et al., 2005).
In contrast to the other pore water species, large differences in the depth profiles of dissolved $\mathrm{Mn}^{2+}$ and $\mathrm{SO}_{4}{ }^{2-}$ are observed between the individual sampling times (Fig. 8). The elevated pore water $\mathrm{Mn}^{2+}$ values in spring could be the result of a temporarily increased input of reactive $\mathrm{Mn}$ oxides at the SWI. The model simulation likely under-predicts the rate of manganese reduction for the spring sampling time. The highly variable shape of the $\mathrm{SO}_{4}{ }^{2-}$ profiles also makes it difficult to define an average pore water profile that can be compared to the model calculated depth distribution. Possible reasons for the observed $\mathrm{SO}_{4}{ }^{2-}$ profile shapes are explored in Section 6.4. 

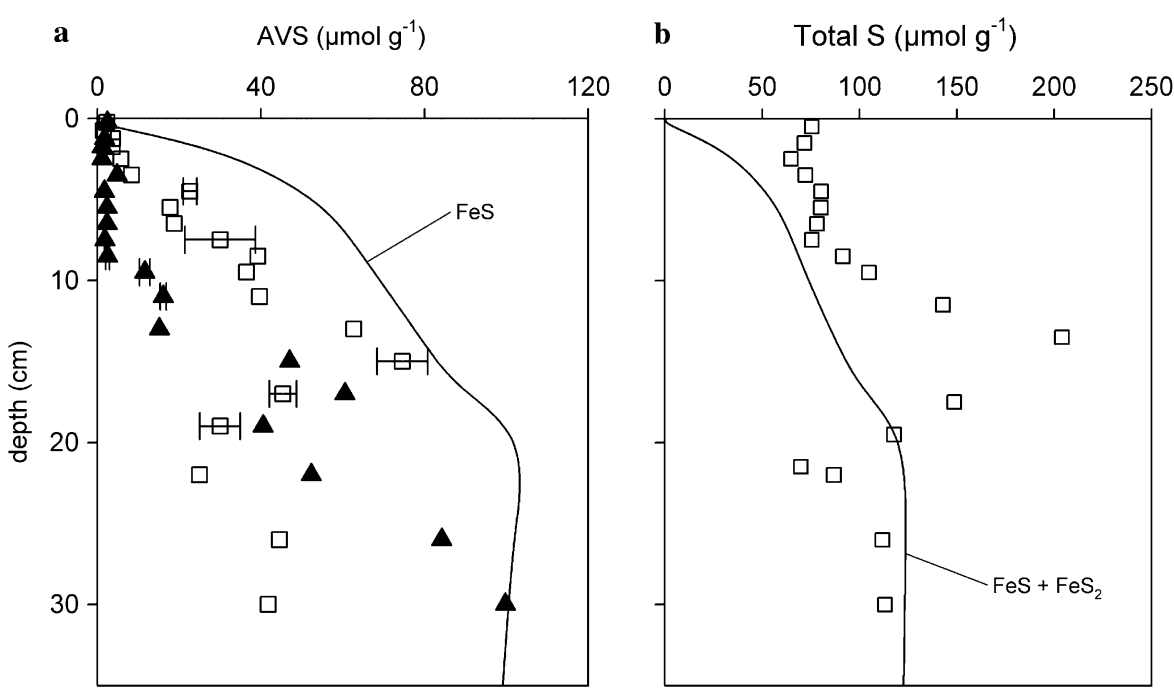

Fig. 7. Acid volatile sulfide (AVS) distributions for late-summer $(\square)$ and spring $(\mathbf{\Delta})$; the solid line represents the modeled FeS concentrations (a). Total sulfur distribution for late-summer $(\square)$, the solid line represents the sum of modeled $\mathrm{FeS}$ and $\mathrm{FeS}_{2}$ concentrations (b). Errors bars are \pm one standard deviations on duplicate or triplicate analyses.
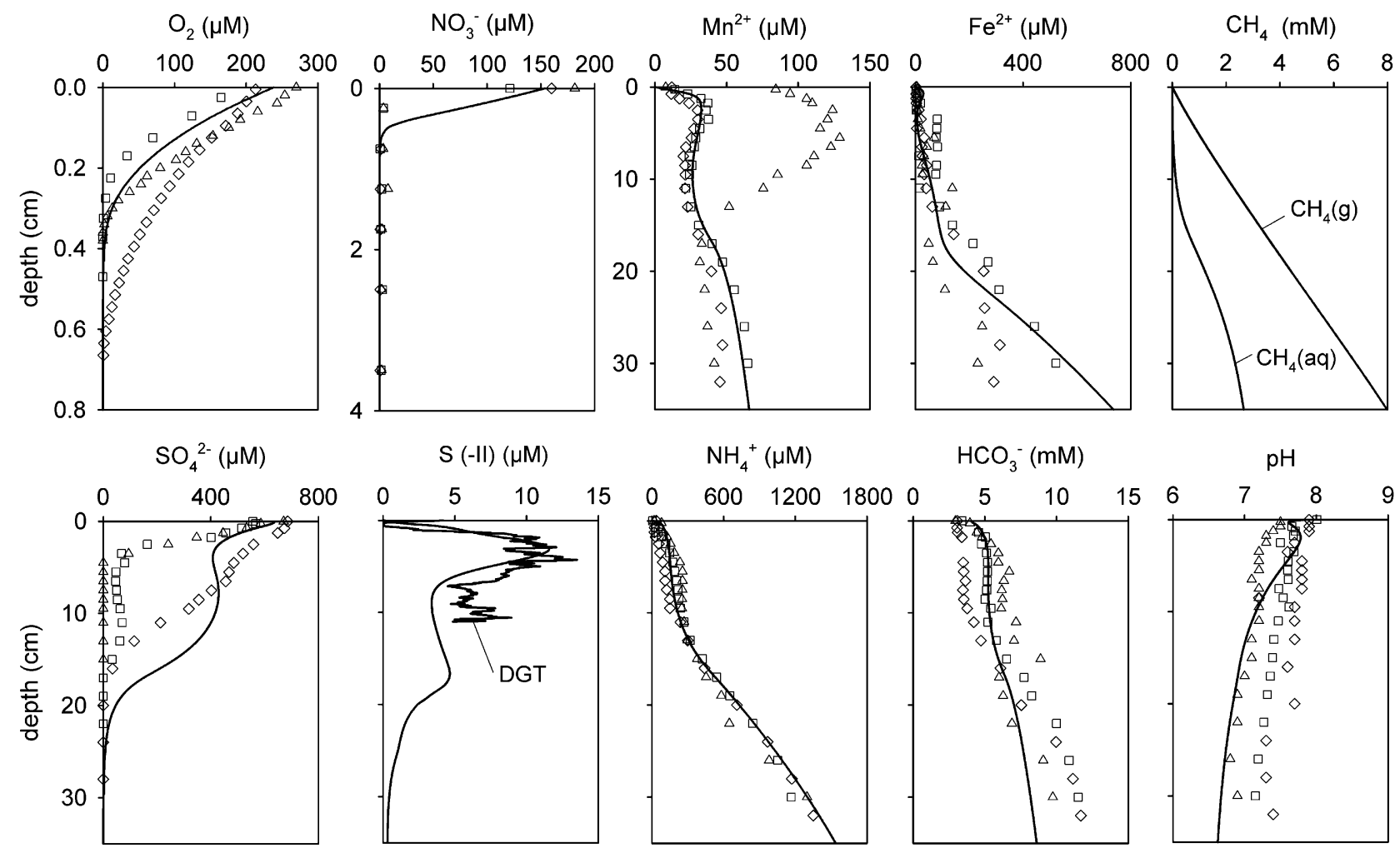

$\mathrm{pH}$

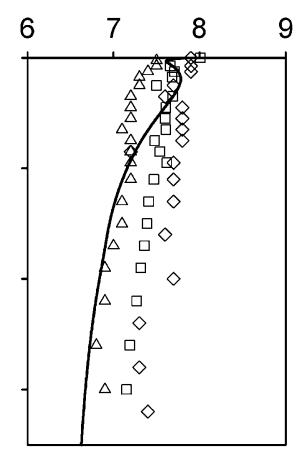

Fig. 8. Pore water profiles for fall $(\diamond)$, late-summer $(\square)$, and spring $(\triangle)$ of dissolved species; solid lines are modeled profiles. The line marked DGT in the $\mathrm{S}(-\mathrm{II})$ plot is the AgI DGT derived sulfide profile measured in the upper $10 \mathrm{~cm}$ of the sediment. In the $\mathrm{HCO}_{3}{ }^{-}$plot, model results correspond to $\mathrm{HCO}_{3}{ }^{-}$ concentrations, while the data points correspond to measurements of DIC (fall) or alkalinity (late-summer and spring). Note different depth scales in the $\mathrm{O}_{2}$ and $\mathrm{NO}_{3}^{-}$plots.

\subsection{Carbon mineralization rates}

High rates of organic matter degradation in the upper millimeters of sediment are needed to reproduce the observed $\mathrm{O}_{2}$ and $\mathrm{NO}_{3}{ }^{-}$profiles (Fig. 8). This is achieved by including a highly reactive fraction (OM1) in the deposited organic matter, but also by explicitly accounting for the enhanced efficiency of $\mathrm{O}_{2}$ and $\mathrm{NO}_{3}{ }^{-}$as TEAs of organic carbon oxidation. Together aerobic respiration and denitrification are responsible for about $90 \%$ of OM1 degradation (Table 6). In contrast, the most important decomposition pathways for the less reactive organic matter pool, 
Table 5

Comparison of maximum model derived rates and experimental rates

\begin{tabular}{|c|c|c|c|c|c|c|c|}
\hline \multicolumn{2}{|c|}{ Model derived maximum rates } & \multicolumn{6}{|l|}{ Experimental rates } \\
\hline Pathway & $\left(\mu \mathrm{mol} \mathrm{cm}{ }^{-3} \mathrm{yr}^{-1}\right)$ & Method & $\begin{array}{l}\text { Mean } \\
\left(\mu \mathrm{mol} \mathrm{cm}{ }^{-3} \mathrm{yr}^{-1}\right)\end{array}$ & $\begin{array}{l}\mathrm{SD}^{\mathrm{a}} \\
\left(\mu \mathrm{mol} \mathrm{cm}{ }^{-3} \mathrm{yr}^{-1}\right)\end{array}$ & $\begin{array}{l}\text { No. } \\
\text { experiments }\end{array}$ & $\begin{array}{l}\text { Depth } \\
\text { range }(\mathrm{cm})\end{array}$ & Date $^{b}$ \\
\hline Denitrification & 713 & Denitrification FTR & 783 & 547 & 12 & $0-4$ & $\mathrm{~S}, \mathrm{LS}, \mathrm{F}$ \\
\hline Sulfate reduction & 25 & Sulfate reduction FTR & 23 & 16 & 8 & $2-4,8-10$ & LS \\
\hline Anoxic pathways ${ }^{c}$ & 220 & Anoxic slurry & 85 & 86 & 19 & $0-20$ & $\mathrm{LS}, \mathrm{F}$ \\
\hline
\end{tabular}

Table 6

Depth integrated rates of carbon mineralization and secondary redox reactions in the upper $30 \mathrm{~cm}$ of sediment

\begin{tabular}{llllc}
\hline \multicolumn{4}{l}{ Primary redox reactions } \\
\hline Reaction & $\mathrm{TEA}$ & $\begin{array}{l}\mathrm{OM} 1 \\
\left(\mu \mathrm{mol} \mathrm{cm} \mathrm{yr}^{-1}\right)\end{array}$ & $\begin{array}{l}\mathrm{OM} 2 \\
\left(\mu \mathrm{mol} \mathrm{cm} \mathrm{cr}^{-2}\right)\end{array}$ & $\%$ total \\
\hline $\mathrm{R} 1, \mathrm{R} 7$ & $\mathrm{O}_{2}$ & 422 & 1.2 & 55 \\
$\mathrm{R} 2, \mathrm{R} 8$ & $\mathrm{NO}_{3}$ & 149 & 15 & 21 \\
$\mathrm{R} 3, \mathrm{R} 9$ & $\mathrm{Mn}(\mathrm{IV})$ & 1.4 & 0.2 & 0.2 \\
$\mathrm{R} 4, \mathrm{R} 10$ & $\mathrm{Fe}(\mathrm{III})$ & 5.1 & 1.3 & 0.8 \\
$\mathrm{R} 5 . \mathrm{R} 11$ & $\mathrm{SO}_{4}$ & 57 & 74 & 17 \\
$\mathrm{R} 6, \mathrm{R} 12$ & $\mathrm{OM}^{\mathrm{a}}$ & 0.0 & 34 & 4.4 \\
$\mathrm{R} 13$ & $\mathrm{OM}^{\mathrm{a}}$ & - & 4.3 & 0.6 \\
Total & & 634 & 130 &
\end{tabular}

Secondary redox reactions

\begin{tabular}{llcc}
\hline Reaction & Code & $\mu \mathrm{mol} \mathrm{cm} \mathrm{cr}^{-2} \mathrm{yr}^{-1}$ & $\mu \mathrm{mol} \mathrm{O} \mathrm{cm}^{-2} \mathrm{yr}^{-1}$ \\
\hline $\mathrm{R} 14$ & nh4ox & 19 & 39 \\
$\mathrm{R} 15$ & tsox & 1.5 & 3.1 \\
$\mathrm{R} 16$ & fesox & 26 & 51 \\
$\mathrm{R} 17$ & mnox & 0.1 & 0.05 \\
$\mathrm{R} 18$ & feox & 9.3 & 2.3 \\
$\mathrm{R} 19$ & ch4ox & 12 & 12 \\
$\mathrm{R} 20$ & femnox & 1.1 & \\
$\mathrm{R} 21$ & ch4so4ox & 0.1 & \\
R22, R23 & tsmnox & 0.5 & \\
$\mathrm{R} 24, \mathrm{R} 25$ & tsfeox & 2.5 & \\
\hline
\end{tabular}

Primary reaction rates are given in units of carbon equivalents, secondary reaction rates refer to the reaction formulas in Table 2 . For secondary oxygenation reactions, rates are also expressed as $\mathrm{O}_{2}$ consumption rates.

${ }^{\text {a }}$ Methanogenesis.

$\mathrm{OM} 2$, are sulfate reduction, methanogenesis and, to a lesser extent, denitrification. The OM1 pool is nearly completely degraded $(99 \%)$ in the upper $2 \mathrm{~cm}$ of the sediment, while only $39 \%$ of OM2 is degraded within the upper $30 \mathrm{~cm}$. Dissimilatory $\mathrm{Fe}$ and Mn-oxide reduction do not contribute significantly to total $\mathrm{C}_{\text {org }}$ mineralization. Limited methane gas formation is predicted to occur in the upper $30 \mathrm{~cm}$ of sediment (Table 6).

The total depth-integrated carbon mineralization rate $\left(764 \mu \mathrm{mol} \mathrm{cm}{ }^{-2} \mathrm{yr}^{-1}\right)$ is at the high end of the range derived by den Heyer and Kalff (1998) from DIC and $\mathrm{CH}_{4}$ accumulation rates in sediment core incubations of nine lakes in Québec (maximum value for profundal cores: $876 \mu \mathrm{mol} \mathrm{cm}^{-2} \mathrm{yr}^{-1}$ ). The relatively high rates at our site reflect the large input of degradable organic matter from the water column, but also the high concentrations of oxygen and nitrate in the bottom waters. Both the modeling results and the direct rate measurements imply order-of-magnitude higher rates of organic carbon degradation by aerobic respiration and denitrification than by the other pathways, in particular sulfate reduction (Table 5). The large contributions of aerobic respiration (55\%) and denitrification $(21 \%)$ to total organic carbon oxidation limit the transfer of potentially degradable organic matter to the deeper sediment. Combined with the relatively high concentration of sulfate in the overlying water, this explains why methanogenesis is not a major pathway of organic matter breakdown at the site studied.

The inferred fraction of total organic carbon oxidation that is due to aerobic respiration (55\%) is much larger than found in the model studies by Van Cappellen and Wang (1995) and van den Berg et al. (2000) of freshwater sediments deposited under oxygenated waters. These authors report contributions in the range 3-12\%. In these studies, however, only a single degradable organic carbon pool is included (the so-called 1-G model), hence limiting how accurately carbon mineralization with depth can be described. In particular, the $1-G$ model approach poorly reproduces the presence of a thin surface layer exhibiting much higher rates of carbon mineralization than the underlying sediment. Additionally, van den Berg et al. (2000) note that their modeled $\mathrm{CH}_{4}$ concentrations exceed saturation values, which may have caused an over-estimation of methane oxidation by $\mathrm{O}_{2}$. Using the STEADYQL model Furrer and Wehrli (1996) estimate that $65 \%$ of total organic carbon mineralization in sediment of eutrophic Lake Sempach (Switzerland) occurs via aerobic respiration. While this estimate is similar to that obtained here, it should be noted that STEADYQL does not account for secondary oxygenation reactions, and thus overestimates the contribution of oxic respiration.

In Fig. 9, the model predicted depth distribution of the rate of sulfate reduction is compared to rates measured with FTRs and a depth distribution derived from an inverse model optimization (Meile et al., 2001). FTR rate measurements were made with sediment from two different depth intervals $(2-4 \mathrm{~cm}$ and $8-10 \mathrm{~cm})$ collected in late summer. FTRs yield potential rates, because $\mathrm{SO}_{4}{ }^{2-}$ is the only 


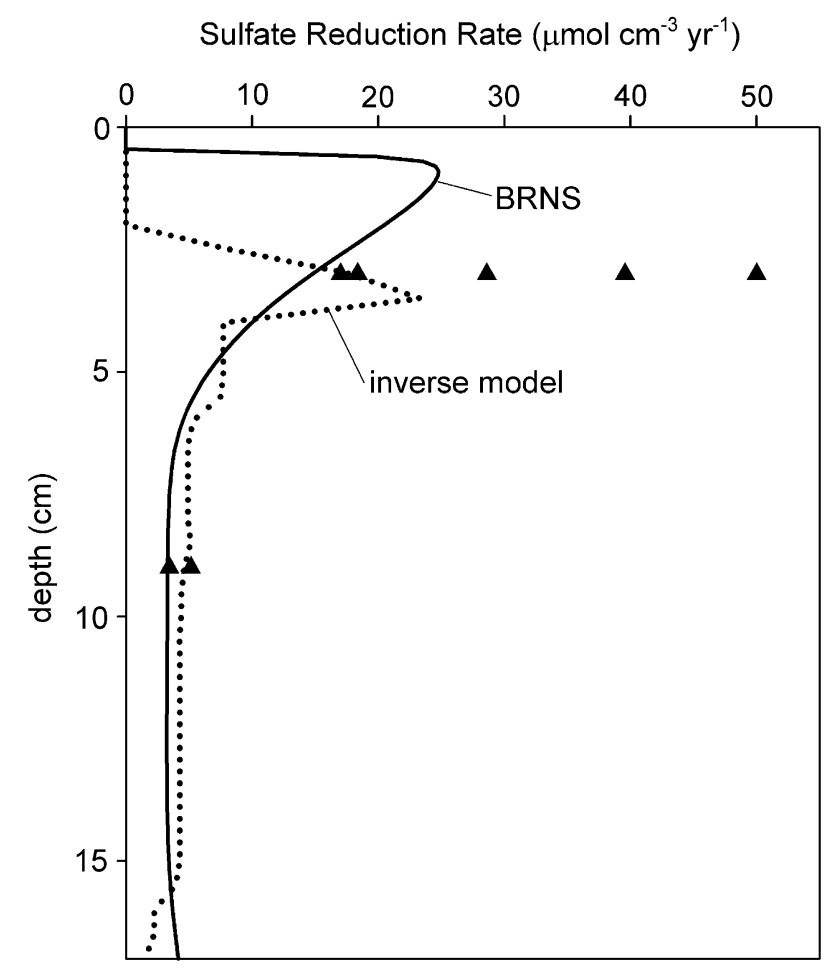

Fig. 9. Sulfate reduction rates in late-summer. The solid line is the rate distribution obtained with the multi-component reaction-transport model $(\mathrm{R} 5+\mathrm{R} 11)$ and the dotted line corresponds to the rate distribution obtained by inverse modeling of the sulfate concentration distribution (Meile et al., 2001). Potential sulfate reduction rates measured in FTR experiments for depth intervals $2-4$ and $8-9 \mathrm{~cm}$ are marked with (ム) symbols.

external TEA supplied to the sediment via the inflow during the experiments (Pallud and Van Cappellen, 2006). Potential rates should therefore provide upper estimates of in situ rates. This can be seen for the $2-4 \mathrm{~cm}$ sediment interval, where the lowest potential rates approach the model predicted in situ rates. In the $8-10 \mathrm{~cm}$ depth interval, potential rates from FTR experiments are close to modeled rates, suggesting that at these depths sulfate reducing activity is mainly limited by the availability of electron donors. This is consistent with the inferred near-complete degradation of the most reactive organic matter (OM1) in the topmost centimeters. Inverse modeling yields the rate of net $\mathrm{SO}_{4}{ }^{2-}$ removal after accounting for diffusion and irrigation. The near-zero values for the net sulfate removal rate in the upper $2 \mathrm{~cm}$ reflect the production of sulfate by sulfide oxidation (Section 6.3) in the top sediment. At greater depths, where sulfide oxidation becomes negligible, the inverse model and the reactive transport model predict similar rates.

The results in Fig. 9 suggest that the model-derived sulfate reduction rates are within the correct order of magnitude and approximately reproduce the vertical distribution. Nonetheless, the seasonal variations in the concentration profiles of $\mathrm{SO}_{4}{ }^{2-}$, but also of other reactive pore water solutes, such as $\mathrm{O}_{2}, \mathrm{NH}_{4}^{+}$and DIC, serve as a reminder that rates of organic matter degradation in the sediment are time-dependent. The observed variations in the concentrations of AVS in the zone of most active sulfate reduction (Fig. 7a) further provide evidence that sulfate reduction rates are changing throughout the year (Leonard et al., 1993).

\subsection{Secondary reactions}

According to the model calculations, secondary oxygenation reactions account for in the order of $20 \%$ of total sediment oxygen consumption, mainly through the oxidation of $\mathrm{FeS}, \mathrm{NH}_{4}^{+}$, and $\mathrm{CH}_{4}$ (aq) (Table 6). The oxidation of $\mathrm{NH}_{4}{ }^{+}$and $\mathrm{FeS}$ regenerate $\mathrm{NO}_{3}{ }^{-}$and $\mathrm{SO}_{4}{ }^{2-}$, which in turn help sustain denitrification and sulfate reduction. Abiotic $\mathrm{Fe}(\mathrm{III})$ reduction by sulfide $\left(19 \mu \mathrm{mol} \mathrm{Fe} \mathrm{cm}^{-2} \mathrm{yr}^{-1}\right)$ and dissimilatory $\mathrm{Fe}(\mathrm{III})$ reduction $\left(25 \mu \mathrm{mol} \mathrm{Fe} \mathrm{cm}^{-2} \mathrm{yr}^{-1}\right)$ are of comparable magnitude. The oxidation of $\mathrm{Fe}^{2+}$ by $\mathrm{O}_{2}\left(9 \mu \mathrm{mol} \mathrm{Fe} \mathrm{cm}{ }^{-2} \mathrm{yr}^{-1}\right)$ exceeds that by $\mathrm{MnO}_{2}(2 \mu \mathrm{mol}$ $\left.\mathrm{Fe} \mathrm{cm}-2 \mathrm{yr}^{-1}\right)$. Reduction of $\mathrm{MnO}_{2}$ by $\mathrm{Fe}^{2+}$ is responsible for $18 \%$ of total manganese reduction. Apart from reaction with $\mathrm{Fe}^{2+}$, the cycling of $\mathrm{Mn}$ does not play an important role in the major elemental cycles at the site (Table 6).

Methane oxidation is predicted to occur primarily via reaction with $\mathrm{O}_{2}\left(12 \mu \mathrm{mol} \mathrm{cm} \mathrm{cm}^{-2} \mathrm{yr}^{-1}\right)$, with a negligible contribution of anaerobic methane oxidation $(0.1 \mu \mathrm{mol}$ $\left.\mathrm{cm}^{-2} \mathrm{yr}^{-1}\right)$. Because, in the model, $\mathrm{CH}_{4}(\mathrm{~g})$ generated in the sediment is assumed to be non-reactive, the calculated rate of methane oxidation represents a conservative estimate. The potential error introduced by neglecting the possible redissolution of gaseous methane in the surface sediment, followed by oxidation, is assessed by running a simulation where all methanogenesis yields $\mathrm{CH}_{4}(\mathrm{aq})$ production. This nearly doubles the methane oxidation rate, from 12 to $22 \mu \mathrm{mol} \mathrm{cm} \mathrm{cr}^{-1}$. The increased methane oxidation rate still has little impact on total oxygen consumption, as the $\mathrm{O}_{2}$ consumption due to methane oxidation rises from 2 to $4 \%$.

\section{3. $\mathrm{Fe}-\mathrm{S}$ cycling}

Iron and sulfur cycling are linked in the reaction network through the formation of $\mathrm{FeS}$ and $\mathrm{FeS}_{2}$, reaction of sulfide with $\mathrm{Fe}$-oxides, and the oxidation of $\mathrm{FeS}$ (Fig. 10). Most of the $\mathrm{Fe}^{2+}$ and S(-II) produced in the sediment forms FeS. Although sulfate reduction is quantitatively a far more important electron sink than iron reduction, the amounts of $\mathrm{S}(-\mathrm{II})$ and $\mathrm{Fe}^{2+}$ produced are relatively similar due to the 8 -fold difference in reaction stoichiometry (Fig. 10 and Table 2). Because of efficient sulfur recycling, the depth-integrated sulfate reduction rate equals nearly twice the $\mathrm{SO}_{4}{ }^{2-}$ influx at the SWI.

Only about $10 \%$ of the $\mathrm{FeS}$ produced in the sediment is converted into pyrite. According to the model calculations, $\mathrm{FeS}$ represents the main burial sink for reactive iron and sulfur (Fig. 10). The simulation, however, tends to overestimate the AVS concentrations (Fig. 7a), implying that the $\mathrm{FeS}$ sink could be somewhat lower than indicated on 


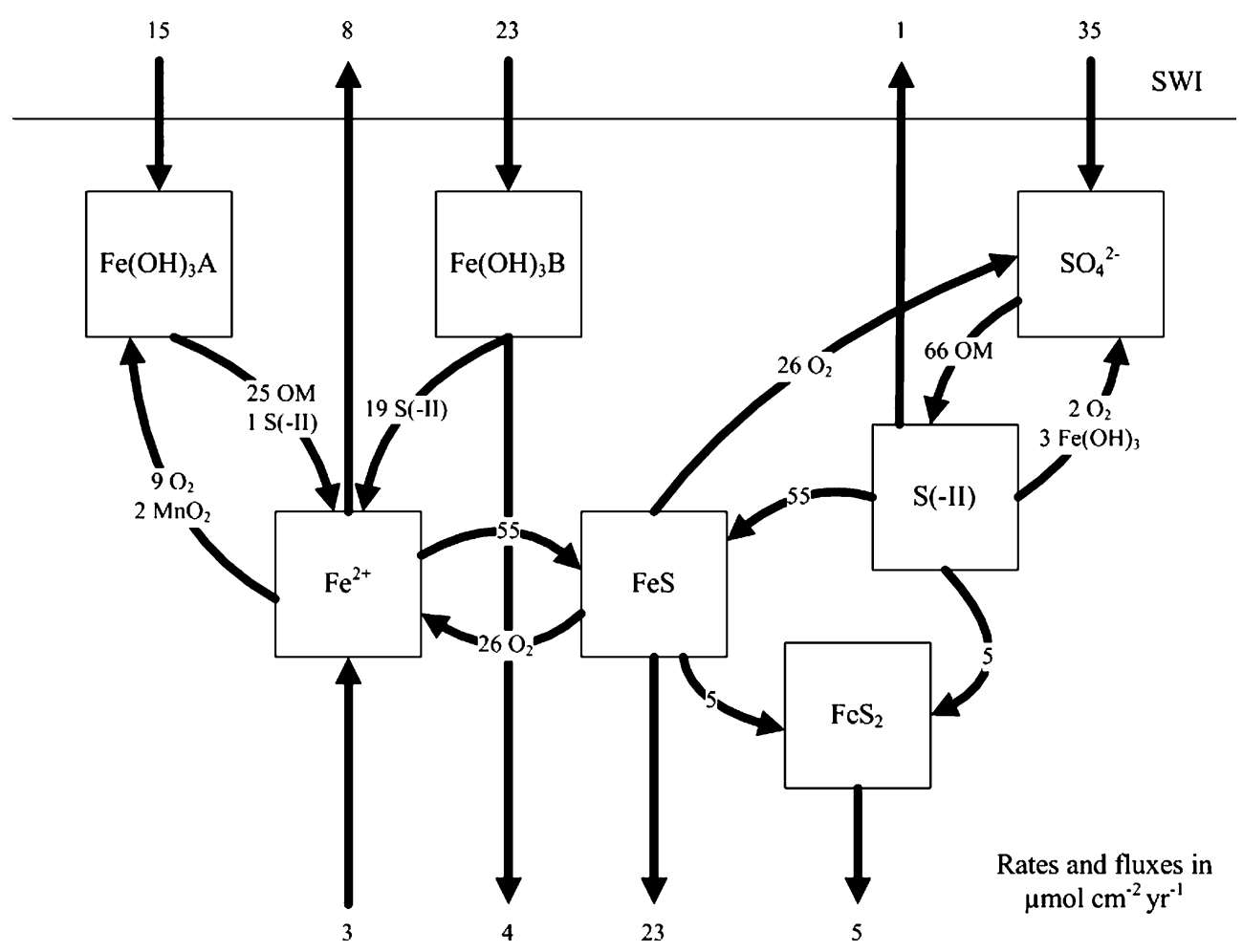

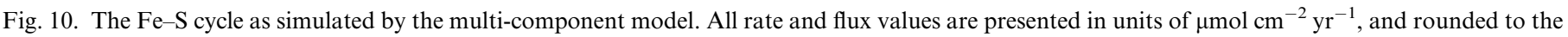
nearest whole number. Rate values are integrated over the upper $30 \mathrm{~cm}$ of sediment. Transport fluxes are indicated at the beginning or ends of the arrows. Values on the arrows are reaction rates; for redox reactions the oxidant or reductant is identified to the right of the rate values. Note that rate values are presented for the reaction stoichiometries listed in Table 2 . $\mathrm{Fe}(\mathrm{OH})_{3} \mathrm{~A}$ is the bioavailable Fe-oxide pool, the $\mathrm{Fe}(\mathrm{OH})_{3} \mathrm{~B}$ pool is only reduced chemically by sulfide.

Fig. 10. Nonetheless, authigenically formed iron sulfides may account for most solid-phase sulfur in the deeper sediment (Fig. 7b). Excess sulfur in the surface sediment may represent particulate sulfur pools not included in the model, such as organically bound $\mathrm{S}$ and elemental $\mathrm{S}$.

Both the chemical extraction data and the model calculations indicate that substantial amounts of reactive $\mathrm{Fe}(\mathrm{III})$ are buried below $30 \mathrm{~cm}$ (Figs. 6 and 10). As reported in a number of studies, a fraction of the chemically reducible $\mathrm{Fe}(\mathrm{III})$ mineral phases is unavailable for microbial respiration (e.g., Wersin et al., 1991; Berg et al., 2003; Hyacinthe and Van Cappellen, 2004). One important biogeochemical consequence of future seawater intrusion in Haringvliet Lake could be the enhanced reductive dissolution of this $\mathrm{Fe}(\mathrm{III})$ pool by sulfide generated by sulfate reduction (Section 6.5).

\subsection{Transport-bioirrigation and bioturbation}

Diffusion and non-local transport (bioirrigation) are both important modes of solute transport in the upper $15 \mathrm{~cm}$ of sediment. Bioirrigation increases the fluxes of $\mathrm{O}_{2}, \mathrm{NO}_{3}{ }^{-}$, and $\mathrm{SO}_{4}{ }^{2-}$ into the sediment (Table 7), causing more $\mathrm{C}_{\text {org }}$ mineralization to be coupled to the soluble TEAs. Overall, increased influx of $\mathrm{O}_{2}$ and enhanced removal of reduced solutes by bioirrigation (Table 7) decreases the fraction of total $\mathrm{O}_{2}$ consumption due to secondary
Table 7

Rates of solute exchange by diffusion and bioirrigation at the SWI

\begin{tabular}{lccc}
\hline Solute & $\begin{array}{l}\text { Diffusion } \\
\left(\mu \mathrm{mol} \mathrm{cm} \mathrm{cm}^{-2} \mathrm{yr}^{-1}\right)\end{array}$ & $\begin{array}{l}\text { Bioirrigation } \\
\left(\mu \mathrm{mol} \mathrm{cm} \mathrm{cm}^{-2} \mathrm{yr}^{-1}\right)\end{array}$ & $\begin{array}{l}\text { Contribution of } \\
\text { bioirrigation }(\%)\end{array}$ \\
\hline $\mathrm{O}_{2}$ & -500 & -31 & 6 \\
$\mathrm{NO}_{3}{ }^{-}$ & -92 & -20 & 18 \\
$\mathrm{Mn}^{2+}$ & 4 & 2 & 36 \\
$\mathrm{SO}_{4}{ }^{2-}$ & -5 & -30 & 86 \\
$\mathrm{CH}_{4}(\mathrm{aq})$ & 0 & 19 & 100 \\
$\mathrm{NH}_{4}{ }^{+}$ & 91 & 27 & 23 \\
$\mathrm{HCO}_{3}{ }^{-}$ & 104 & 165 & 62 \\
\hline
\end{tabular}

Negative values denote fluxes into sediment.

redox reactions. In a simulation where all bioirrigation coefficients are set to zero, the contribution of secondary redox reactions to total $\mathrm{O}_{2}$ consumption increases from $19 \%$ to $24 \%$. In the same simulation, methanogenesis increases from $5 \%$ to $15 \%$ of total $\mathrm{C}_{\text {org }}$ decomposition.

Recent work has cautioned against the use of a single depth distribution of the irrigation coefficient for all pore water solutes (Aller, 2001; Berg et al., 2003; Grigg et al., 2005; Meile et al., 2005). Following the suggestions of Berg et al. (2003) and Meile et al. (2005), we therefore reduced the $\alpha$ values for $\mathrm{Fe}^{2+}$ and $\mathrm{Mn}^{2+}$, relative to those of the conservative ions $\mathrm{Na}^{+}$and $\mathrm{Cl}^{-}$(Section 4.2). Note that although the model assumes that aqueous $\mathrm{Fe}^{2+}$ is not subject to transport by irrigation $(\alpha=0)$, the $\mathrm{Fe}^{2+}$ profile is 
affected by the enhanced pore water mixing (Fig. 8). The lack of significant build-up of pore water $\mathrm{Fe}^{2+}$ in the upper $15 \mathrm{~cm}$ is due in part to the enhanced downward transport of oxygenated bottom water, fueling oxidation of $\mathrm{Fe}^{2+}$ in the irrigated zone.

To some degree, the irrigation coefficients of all reactive solute species should deviate from those of conservative tracers (Meile et al., 2005). This could be particularly important for $\mathrm{SO}_{4}{ }^{2-}$, whose supply from the water column is strongly affected by irrigation (Table 7). According to Meile et al. (2005), $\mathrm{SO}_{4}{ }^{2-}$ exhibits lower than average irrigation coefficients. This could help explain the mismatch between measured and computed $\mathrm{SO}_{4}{ }^{2-}$ profiles. The sensitivity of the $\mathrm{SO}_{4}{ }^{2-}$ pore water distribution to the irrigation intensity is illustrated in Fig. 11a. As can be seen, reducing the irrigation coefficient of $\mathrm{SO}_{4}{ }^{2-}$ yields pore water profiles that more closely resemble those observed during spring and late summer. The fall data, however, suggests a possible enhancement of the irrigation intensity. Uncertainties in the transport properties of the pore water solutes directly affect the estimated reaction rates. For instance, reductions of $\alpha_{0}$ for $\mathrm{SO}_{4}{ }^{2-}$ by $50 \%$ and $100 \%$ cause the calculated integrated rate of sulfate reduction to decrease by $6.1 \%$ and $32 \%$, respectively.

Changes in the particle mixing regime also affect the rates of primary and secondary redox reactions. Some of the effects are examined by changing the value of $D_{\mathrm{b}} 0$ in the equation for the biodiffusion coefficient distribution listed in Table 4. The reactive iron and sulfur species are particularly sensitive to the degree of sediment mixing (Figs. $11 \mathrm{~b}$ and c). Increasing $D_{\mathrm{b}} 0$ increases sulfate removal from the pore waters (Fig. 11b), as the highly reactive organic matter (OM1) is transported deeper into the sediment where it is utilized by sulfate reduction. Lowering
$D_{\mathrm{b}} 0$ has the opposite effects on the $\mathrm{SO}_{4}{ }^{2-}$ concentrations and sulfate reduction rates. In the low mixing simulation $\left(D_{\mathrm{b}} 0=1 \mathrm{~cm}^{2} \mathrm{yr}^{-1}\right)$, a significant build-up of reactive $\mathrm{Fe}(\mathrm{III})$ precipitates is observed in the upper $5 \mathrm{~cm}$ of the sediment, causing the appearance of a subsurface concentration maximum (Fig. 11c). Such an accumulation of $\mathrm{Fe}$ (III) oxides at the oxic-suboxic interface has been observed in lake sediments, and may increase the importance of dissimilatory iron reduction (Thomsen et al., 2004).

\subsection{Estuarine restoration}

The model is used to examine potential changes in benthic biogeochemistry that could result from the restoration of estuarine conditions at our study site. In particular, we examine how the primary and secondary redox reaction dynamics would respond to changes in bottom water chemistry, deposition of organic matter and the bioturbation regime. The sensitivity to these changes is initially assessed using steady state solutions of the model (Table 8). Then, a transient simulation is performed to illustrate the time scales over which sediment biogeochemistry is expected to respond to a switch from lacustrine to estuarine conditions (Fig. 12).

Some of the environmental forcings that will change upon the (regulated) intrusion of seawater in the Haringvliet are predictable, while others are more speculative. For instance, water column salinization will undoubtedly increase the $\mathrm{SO}_{4}{ }^{2-}$ concentration at the SWI. However, while increased salinity stratification is expected to result in lower bottom water $\mathrm{O}_{2}$ concentrations, it is not known to what extent $\mathrm{O}_{2}$ may be depleted. The same is true for the OM deposition fluxes, which are likely to decrease, as increased exchange of water with the adjacent coastal zone will
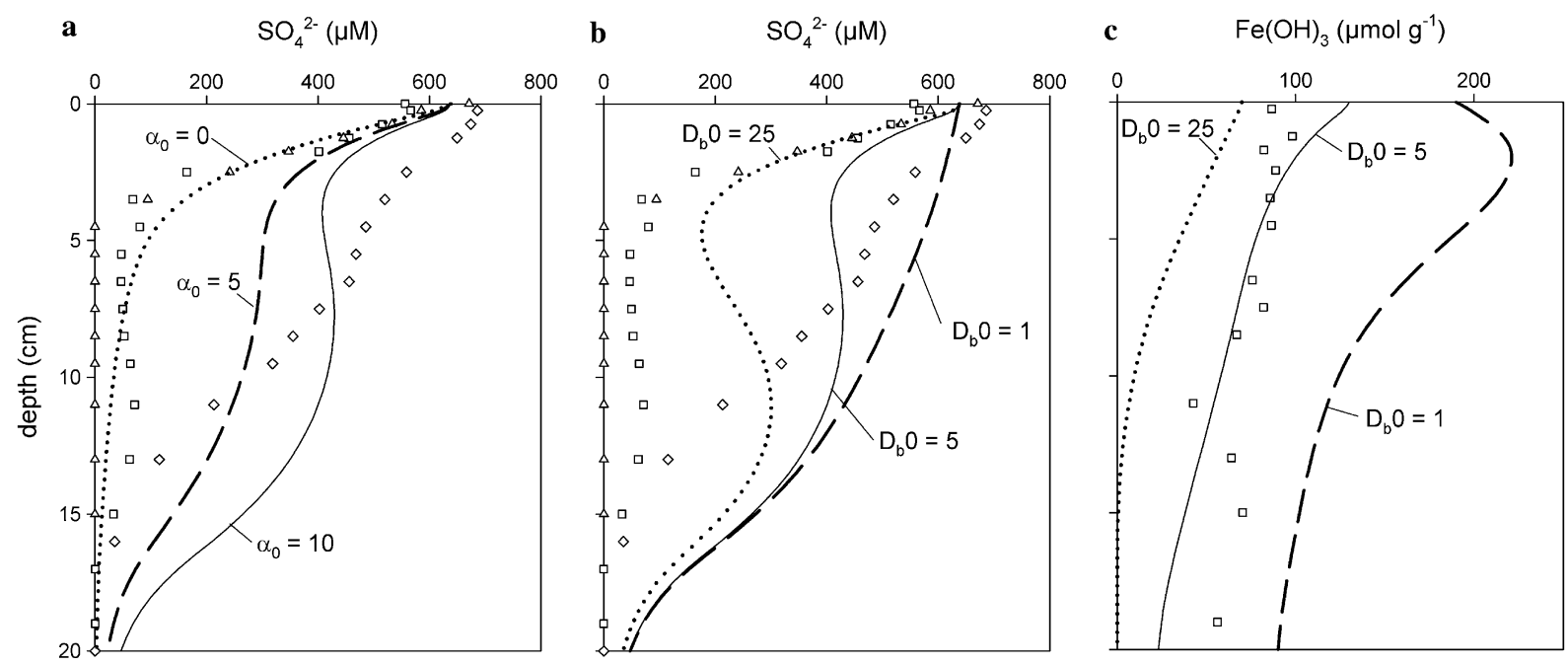

Fig. 11. Model sensitivity to bioirrigation is shown with the concentration distribution of $\mathrm{SO}_{4}{ }^{2-}$ (a) where the solid line is the baseline simulation $\left(\alpha_{0}=10 \mathrm{yr}^{-1}\right)$, the dashed line is with $\alpha_{0}=5 \mathrm{yr}^{-1}$, and the dotted line is with $\alpha_{0}=0 \mathrm{yr}^{-1}$. Model sensitivity to the particle mixing intensity $\left(D_{\mathrm{b}} 0\right)$ is shown using the concentration distributions of $\mathrm{SO}_{4}{ }^{2-}$ (b) and $\Sigma \mathrm{Fe}(\mathrm{OH})_{3}$ (c). The dotted lines correspond to simulations with $D_{\mathrm{b}} 0=25 \mathrm{~cm}^{2} \mathrm{yr}{ }^{-1}$, the solid lines with $D_{\mathrm{b}} 0=5 \mathrm{~cm}^{2} \mathrm{yr}^{-1}$ and the dashed lines with $D_{\mathrm{b}} 0=1 \mathrm{~cm}^{2} \mathrm{yr}^{-1}$. Field data are presented with the following symbols: fall $(\diamond)$, late-summer $(\square)$, and spring $(\triangle)$. 
Table 8

Responses of sediment biogeochemistry to possible changes in site conditions resulting from estuarine restoration

\begin{tabular}{lllll}
\hline Scenario $^{\mathrm{a}}$ & $\begin{array}{l}\text { Oxic respiration } \\
\left(\mu \mathrm{mol} \mathrm{cm} \mathrm{yr}^{-2}\right)\end{array}$ & $\begin{array}{l}\text { Sulfate reduction } \\
\left(\mu \mathrm{mol} \mathrm{cm} \mathrm{cm}^{-2}\right)\end{array}$ & $\begin{array}{l}\text { FeS oxidation } \\
\left(\mu \mathrm{mol} \mathrm{cm}^{-2} \mathrm{yr}^{-1}\right)\end{array}$ & $\begin{array}{l}\text { Fe-oxide reduction by sulfide } \\
\left(\mu \mathrm{mol} \mathrm{cm}^{-2} \mathrm{yr}^{-1}\right)\end{array}$ \\
\hline Existing conditions & 423 & 131 & 26 & 2.5 \\
$+\mathrm{SO}_{4}{ }^{2-}$ & 421 & 170 & 32 & 3.0 \\
$+\mathrm{SO}_{4}{ }^{2-},-\mathrm{O}_{2}$ & 327 & 209 & 26 & 3.3 \\
$+\mathrm{SO}_{4}^{2-},-\mathrm{OM}$ & 271 & 24 & 1.3 & 0.2 \\
$+\mathrm{SO}_{4}{ }^{2-},+D_{\mathrm{b}} 0$ & 348 & 239 & 33 & 3.8 \\
$+\mathrm{SO}_{4}^{2-},+\lambda$ & 414 & 177 & 25 & 3.0 \\
$+\mathrm{SO}_{4}{ }^{2-},-\mathrm{O}_{2},-\mathrm{OM},+D_{\mathrm{b}} 0,+\lambda$ & 155 & 90 & & 0.9 \\
\hline
\end{tabular}

The depth-integrated rates are derived from steady-state model simulations.

${ }^{\mathrm{a}}+\mathrm{SO}_{4}{ }^{2-}$, SWI concentration increased to $10 \mathrm{mM} ;-\mathrm{O}_{2}$, SWI concentration decreased to $120 \mu \mathrm{M} ;-\mathrm{OM}$, input flux of OM1 and OM2 reduced by $50 \%$; $+D_{\mathrm{b}} 0$, value at SWI increased to $25 \mathrm{~cm}^{2} \mathrm{yr}^{-1}$ (increased mixing intensity); $+\lambda$, value increased to $5 \mathrm{~cm}$ (increased mixing depth).

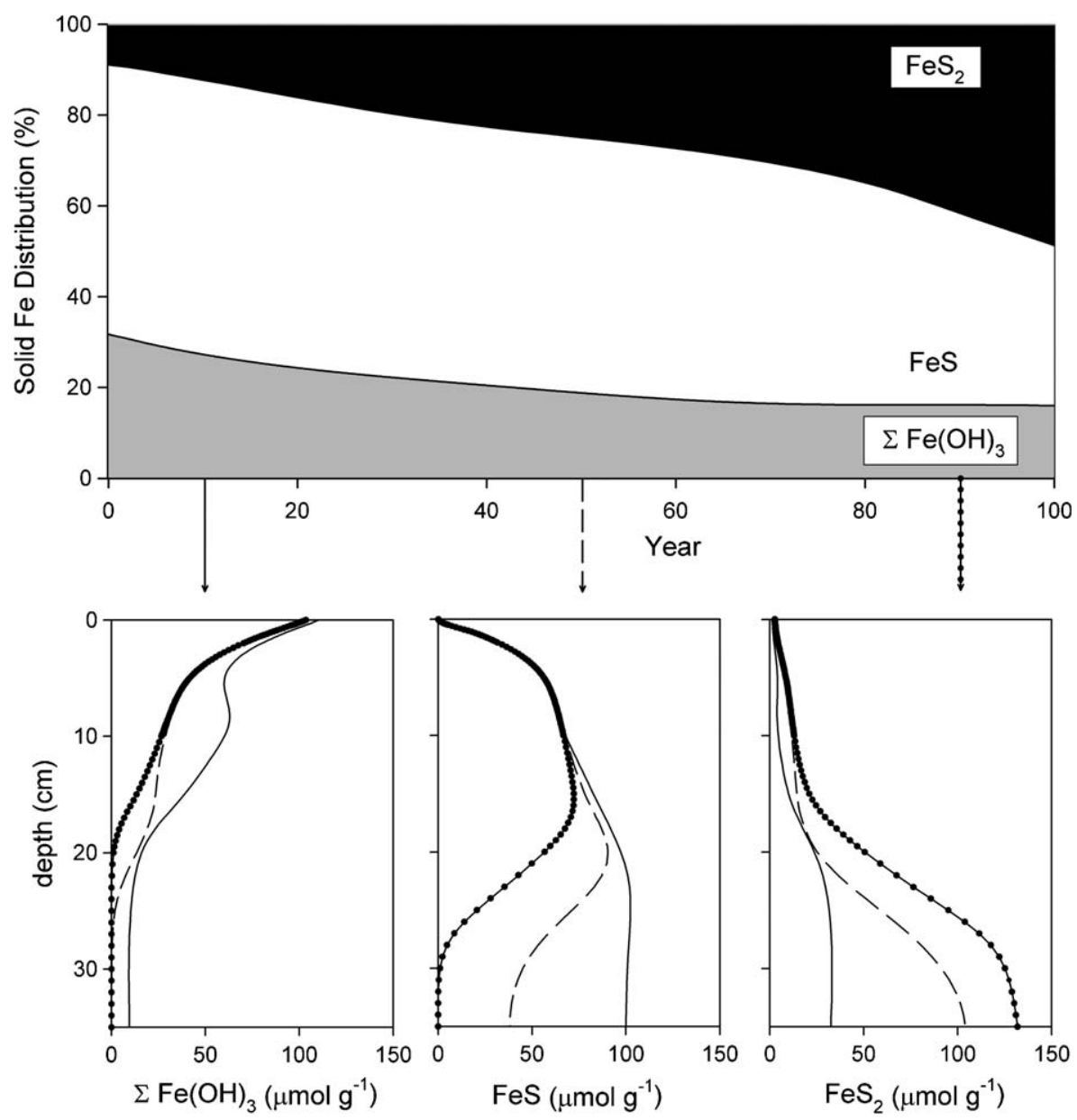

Fig. 12. Transient simulation of solid-phase iron speciation in the sediment following an increase in the bottom water $\mathrm{SO}_{4}{ }^{2-}$ concentration from 0.6 to $10 \mathrm{mM}$. The upper plot displays the concentrations of the $\Sigma \mathrm{Fe}(\mathrm{OH})_{3}, \mathrm{FeS}$, and $\mathrm{FeS}_{2}$ pools, integrated over the upper $30 \mathrm{~cm}$ of sediment. The lower plots show the depth profiles of the three solid Fe pools for simulation times of 10 years (solid line), 50 years (dashed line), and 90 years (dotted line).

enhance the export of nutrients and particulate matter from the Haringvliet.

Increasing the sulfate concentration at the SWI to $10 \mathrm{mM}$ from the current $0.6 \mathrm{mM}$, effectively suppresses methanogenesis in the upper $30 \mathrm{~cm}$ of sediment. The increase in sulfate reduction rate with higher $\mathrm{SO}_{4}{ }^{2-}$ availability is further enhanced by lowering the $\mathrm{O}_{2}$ concentration in the overlying water (Table 8). Nevertheless, the relative increases in the rate of sulfate reduction are relatively small, given the large imposed changes in bottom water chemistry. This reflects the overall limitation of sediment respiration by the supply of degradable organic matter. Hence, a reduction of the OM influx by $50 \%$ causes a drop in the sulfate reduction rate by nearly an order of magnitude, even when the $\mathrm{SO}_{4}{ }^{2-}$ concentration in the bottom water is maintained at $10 \mathrm{mM}$ (Table 8). Under these 
conditions, the relative contributions of aerobic respiration and denitrification to total $\mathrm{C}_{\text {org }}$ degradation increase at the expense of that of sulfate reduction. The lower input of $\mathrm{OM}$ also results in a reduced redox cycling of $\mathrm{Fe}$ and $\mathrm{S}$ in the sediment (Wijsman et al., 2002), as illustrated by the much lower rates of $\mathrm{FeS}$ oxidation and $\mathrm{Fe}(\mathrm{III})$ oxide reduction by sulfide (Table 8 ).

The current benthic fauna in the Haringvliet can be characterized as poor (Smit et al., 1997). Restoration of estuarine conditions is expected to increase the density and diversity of the macroinvertebrate community in the downstream portion of the Haringvliet. Most likely this will intensify and deepen bioturbation of the sediment. In the model simulations, bioturbation was modified by either increasing the value of $D_{\mathrm{b}} 0$, which controls the intensity of mixing, or by extending the depth of mixing by increasing the depth attenuation parameter, $\lambda$. Enhanced mixing promotes sulfate reduction over aerobic degradation (Table 8), as reactive $\mathrm{OM}$ is mixed below the oxygen penetration depth (see also Section 6.4). The rates of FeS oxidation and Fe-oxide reduction by sulfide also increase with greater mixing, as the latter intensifies the exchanges between the oxidized and reduced portions of the sediment. Overall, increasing $D_{\mathrm{b}} 0$ has a greater impact on sediment biogeochemistry than increasing the mixing depth.

The simulation results in Table 8 illustrate the broad range of responses that can be expected upon estuarine restoration. To use the model for environmental forecasting thus depends critically on accurately constraining future changes in benthic forcing functions. An important aspect of the model is its ability to simulate the coupled effects of multiple environmental changes. This is illustrated by the last scenario in Table 8, which combines the various postulated changes in bottom water chemistry, OM deposition and bioturbation regime. This scenario results in lower mineralization rates, due to the decrease in OM input (Table 8). However, the integrated rates of sulfate reduction, FeS oxidation, and sulfide oxidation of Fe-oxides are greater in the combined scenario than expected when only the OM input is reduced, because of the counteracting effect of enhanced mixing.

The results summarized in Table 8 provide no information on the time required for the benthic system to adjust to changing environmental conditions. The temporal response of sediment processes to salinization is addressed with a transient simulation using the steady-state model solution for the present conditions as initial condition. As a perturbation, we impose an instantaneous increase of the $\mathrm{SO}_{4}{ }^{2-}$ concentration at the SWI from 0.6 to $10 \mathrm{mM}$, while all other conditions are kept the same. This perturbation is selected, because estuarine restoration will definitely lead to a significant increase of the $\mathrm{SO}_{4}{ }^{2-}$ levels in the bottom water at the site.

The transient calculations indicate that increased $\mathrm{SO}_{4}{ }^{2-}$ availability at the SWI allows sulfate reduction to immediately suppress methanogenesis in the upper $30 \mathrm{~cm}$ of sediment (results not shown). The integrated rates of organic matter degradation by $\mathrm{O}_{2}, \mathrm{NO}_{3}{ }^{-}$, and $\mathrm{SO}_{4}{ }^{2-}$ adjust to their new steady state values within the first few years. The enhanced production of sulfide by sulfate reduction also leads to further transformation of reactive $\mathrm{Fe}$ (III) oxides to iron sulfides. However, the changes in solid-phase Fe speciation require time scales of several decades and more (Fig. 12). During the first 50 years of the simulation the reactive Fe-oxide concentrations in the sediment decline, while those of pyrite increase. After the reactive Fe(III) oxide content reaches its new steady state, conversion of $\mathrm{FeS}$ to pyrite continues, gradually increasing the amount of pyrite accumulating in the sediment. As shown by Fig. 12, the conversion of $\mathrm{FeS}$ to $\mathrm{FeS}_{2}$ is still ongoing 100 years after the imposed increase in $\mathrm{SO}_{4}{ }^{2-}$ concentration at the SWI. Thus, the simulation results imply that the changes in sediment biogeochemistry caused by the planned restoration of estuarine conditions may occur over a wide range of temporal scales. In particular, the predicted changes in solid-state $\mathrm{Fe}$ speciation may have long-term consequences for the biogeochemical cycling of phosphorus (Caraco et al., 1990; Gunnars and Blomqvist, 1997) and trace metals (Huerta-Diaz et al., 1998) in the Haringvliet.

\section{Conclusions}

Interpretation of chemical sediment and pore water data with a reaction transport model allows us to quantify the rates of primary and secondary redox reactions in sediment of the coastal Haringvliet Lake. The model simultaneously reproduces the depth-dependent trends of multiple constituents, providing strong evidence that it captures the essence of the important reaction and transport processes taking place at the site.

Oxic degradation and denitrification occur at high rates in a shallow zone near the sediment-water interface, and oxidize most $(76 \%)$ of the degradable organic carbon input. Below this zone, sulfate reduction and methanogenesis are the dominant primary reaction pathways, but proceed at much slower rates due to lower reactivity of $\mathrm{C}_{\text {org }}$ and less efficient degradation under anoxic conditions. Secondary redox reactions account for only $20 \%$ of the total $\mathrm{O}_{2}$ consumption, which contrasts with many other eutrophic lakes where methanogenesis is the dominant degradation pathway. Dissimilatory $\mathrm{Mn}(\mathrm{IV})$ and $\mathrm{Fe}(\mathrm{III})$ reduction are not important pathways of $\mathrm{C}_{\text {org }}$ decomposition, despite the presence of chemically reducible $\mathrm{Mn}$ and $\mathrm{Fe}$ mineral phases.

Bioirrigation and bioturbation have a major impact on primary and secondary reaction rates and chemical distributions, emphasizing the link between biogeochemical cycling and the activity of benthic fauna. Better representations and parameterizations of biologically mediated transport processes in reactive transport models remain crucial for improving our quantitative understanding of sediment biogeochemical processes.

Model simulations illustrate the wide range of potential consequences of estuarine restoration for sediment 
biogeochemistry. The results imply that, as a result of increased concentrations of sulfate in the bottom water, sulfate reduction will rapidly suppress methanogenesis at the site studied. Other changes in benthic biogeochemical dynamics, however, will depend on how the production and deposition of degradable organic matter respond to the restoration of estuarine conditions. In addition, the establishment of a new benthic infaunal community adapted to the increased salinity will most likely modify the transport regime and, hence, the biogeochemical cycling in the sediments.

\section{Acknowledgments}

We gratefully acknowledge the crew of R.V. Navicula and members of the Utrecht University geochemistry research group for their help in the field and laboratory. We thank Y. van Lith, D. Los, and C. Pallud for sharing their rate measurement data, and A. Dale and C. Meile for assistance with the modeling. The manuscript benefited from discussions with P. Regnier and G. Zwolsman, and the comments of three anonymous reviewers. The Netherlands Institute for Inland Water Management and Waste Water Treatment (RIZA) financially supported the fieldwork and R.W.C. The Netherlands Organization for Scientific Research (NWO) provided support through the Pioneer (P.V.C.) and VENI (A.M.L.) programs. C.P.S. was supported by a fellowship of the Royal Netherlands Academy of Arts and Sciences (KNAW).

\section{Associate editor: Donald E. Canfield}

\section{References}

Aguilera, D.R., Jourabchi, P., Spiteri, C., Regnier, P., 2005. A knowledgebased reactive transport approach for the simulation of biogeochemical dynamics in earth systems. Geochem. Geophys. Geosys. 6, Q07012.

Aller, R.C., 2001. Transport and reactions in the bioirrigated zone. In: Boudreau, B.P., Jørgensen, B.B. (Eds.), The Benthic Boundary Layer. Oxford University Press, Oxford, pp. 269-301.

Amberg, G., Tonhard, R., Winkler, C., 1999. Finite element simulations using symbolic computing. Math. Comput. Simul. 49, 257-274.

Anonymous, 1998. MER beheer Haringvlietsluizen report (Environmental Impact Report-Haringvliet dam management). Rijkswaterstaat directie Zuid-Holland, APV 98.186 (in Dutch).

APHA, 1985. Standard Methods for the Examination of Water and Wastewater. American Public Health Association, Washington, DC.

Bastviken, D., Persson, L., Odham, G., Tranvik, L., 2004. Degradation of dissolved organic matter in oxic and anoxic lake water. Limnol. Oceanogr. 49, 109-116.

Berg, P., Rysgaard, S., Thamdrup, B., 2003. Dynamic modeling of early diagenesis and nutrient cycling. A case study in an Arctic marine sediment. Am. J. Sci. 303, 905-955.

Berner, R.A., 1980. Early Diagenesis. A Theoretical Approach. Princeton University Press, Princeton, NJ.

Boudreau, B.P., 1996. The diffusive tortuosity of fine-grained unlithified sediments. Geochim. Cosmochim. Acta 60, 3139-3142.

Boon, A.R., Duineveld, G.C.A., 1998. Chlorophyll $a$ as a marker for bioturbation and carbon flux in southern and central North Sea sediments. Mar. Ecol. Prog. Ser. 162, 33-43.
Cai, W.J., Wang, Y., 1998. The chemistry, fluxes and sources of carbon dioxide in the estuarine waters of the Satila and Altamaha Rivers, Georgia. Limnol. Oceanogr. 43, 657-668.

Canfield, D.E., Thamdrup, B., Hansen, J.W., 1993. The anaerobic degradation of organic-matter in Danish coastal sediments-iron reduction, manganese reduction, and sulfate reduction. Geochim. Cosmochim. Acta 57, 3867-3883.

Capone, D.G., Kiene, R.P., 1988. Comparison of microbial dynamics in marine and fresh-water sediments - contrasts in anaerobic carbon catabolism. Limnol. Oceanogr. 33, 725-749.

Caraco, N., Cole, J., Likens, G.E., 1990. A comparison of phosphorus immobilization in sediments of fresh-water and coastal marine systems. Biogeochemistry 9, 277-290.

Chilakapati, A., 1995. RAFT: A Simulator for Reactive Flow and Transport of Groundwater Contaminants. Pacific Northwest Laboratory, Internal Report 10636.

Cline, J.D., 1969. Spectrophotometric determination of hydrogen sulfide in natural waters. Limnol. Oceanogr. 14, 454- 458.

Dauwe, B., Middelburg, J.J., Herman, P.M.J., 2001. Effect of oxygen on the degradability of organic matter in subtidal and intertidal sediments of the North Sea area. Mar. Ecol. Prog. Ser. 215, 13-22.

Davison, W., Phillips, N., Tabner, B.J., 1999. Soluble iron sulfide species in natural waters: reappraisal of their stoichiometry and stability constants. Aquat. Sci. 61, 23-43.

de Jonge, V.N., de Jong, D.J., 2002. Ecological restoration in coastal areas in the Netherlands: concepts, dilemmas and some examples. Hydrobiologia 478, 7-28.

den Heyer, C., Kalff, J., 1998. Organic matter mineralization rates in sediments: a within- and among-lake study. Limnol. Oceanogr. 43, 695-705.

Elsgaard, L., Jørgensen, B.B., 1992. Anoxic transformations of radiolabeled hydrogen-sulfide in marine and fresh-water sediments. Geochim. Cosmochim. Acta 56, 2425-2435.

Ferguson, H.A., Wolff, W.J., 1984. The Haringvliet-Project: the development of the Rhine-Meuse Estuary from tidal inlet to stagnant freshwater lake. Water Sci. Technol. 16, 11-26.

Fossing, H., Berg, P., Thamdrup, B., Rysgaard, S., Sorensen, H.M., Nielsen, K., 2004. A model set-up for an oxygen and nutrient flux model for Aarhus Bay (Denmark). National Environmental Research Institute, Denmark, NERI Technical Report No. 483.

Froelich, P.N., Klinkhammer, G.P., Bender, M.L., Luedtke, N.A., Heath, G.R., Cullen, D., Dauphin, P., Hammond, D., Hartman, B., Maynard, V., 1979. Early oxidation of organic matter in pelagic sediments of the eastern equatorial Atlantic: Suboxic diagenesis. Geochim. Cosmochim. Acta 43, 1075-1090.

Furrer, G., Wehrli, B., 1996. Microbial reactions, chemical speciation, and multicomponent diffusion in porewaters of a eutrophic lake. Geochim. Cosmochim. Acta 60, 2333-2346.

Gallon, C., Tessier, A., Gobeil, C., Alfaro-De La Torre, M.C., 2004. Modeling diagenesis of lead in sediments of a Canadian Shield lake. Geochim. Cosmochim. Acta 68, 3531-3545.

Grigg, N.J., Boudreau, B.P., Webster, I.T., Ford, P.W., 2005. The nonlocal model of porewater irrigation: limits to its equivalence with a cylinder diffusion model. J. Mar. Res. 63, 437-455.

Gunnars, A., Blomqvist, S., 1997. Phosphate exchange across the sediment-water interface when shifting from anoxic to oxic conditions - an experimental comparison of freshwater and brackish-marine systems. Biogeochemistry 37, 203-226.

Hamilton-Taylor, J., Davison, W., Morfett, K., 1996. The biogeochemical cycling of $\mathrm{Zn}, \mathrm{Cu}, \mathrm{Fe}, \mathrm{Mn}$, and dissolved organic $\mathrm{C}$ in a seasonally anoxic lake. Limnol. Oceanogr. 41, 408-418.

Hedges, J.I., Keil, R.G., 1995. Sedimentary organic matter preservation: an assessment and speculative synthesis. Mar. Chem. 49, 81-115.

Holmer, M., Storkholm, P., 2001. Sulphate reduction and sulphur cycling in lake sediments: a review. Freshwater Biol. 46, 431-451.

Huerta-Diaz, M.A., Tessier, A., Carignan, R., 1998. Geochemistry of trace metals associated with reduced sulfur in freshwater sediments. Appl. Geochem. 13, 213-233. 
Hunter, K.S., Wang, Y.F., Van Cappellen, P., 1998. Kinetic modeling of microbially-driven redox chemistry of subsurface environments: coupling transport, microbial metabolism and geochemistry. J. Hydrol. 209, 53-80.

Hyacinthe, C., Van Cappellen, P., 2004. An authigenic iron phosphate phase in estuarine sediments: composition, formation and chemical reactivity. Mar. Chem. 91, 227-251.

Jourabchi, P., Van Cappellen, P., Regnier, P., 2005. Quantitative interpretation of $\mathrm{pH}$ distributions in aquatic sediments: A reactiontransport modeling approach. Am. J. Sci. 305, 919-956.

Koelmans, A.A., 1998. Geochemistry of suspended and settling solids in two freshwater lakes. Hydrobiologia 364, 15-29.

Kostka, J.E., Luther, G.W., 1994. Partitioning and speciation of solidphase iron in salt-marsh sediments. Geochim. Cosmochim. Acta 58, $1701-1710$

Kristensen, E., 2000. Organic matter diagenesis at the oxic/anoxic interface in coastal marine sediments, with emphasis on the role of burrowing animals. Hydrobiologia 426, 1-24.

Leonard, E.N., Mattson, V.R., Benoit, D.A., Hoke, R.A., Ankley, G.T., 1993. Seasonal variation of acid volatile sulfide concentration in sediment cores from three Minnesota lakes. Hydrobiologia 371, 87-95.

Martens, C.S., Albert, D.B., Alperin, M.J., 1998. Biogeochemical processes controlling methane in gassy coastal sediments-Part 1. A model coupling organic matter flux to gas production, oxidation and transport. Cont. Shelf Res. 18, 1741-1770.

Meile, C., Berg, P., Van Cappellen, P., Tuncay, K., 2005. Solute-specific pore water irrigation: implications for chemical cycling in early diagenesis. J. Mar. Res. 63, 601-621.

Meile, C., Koretsky, C.M., Van Cappellen, P., 2001. Quantifying bioirrigation in aquatic sediments: an inverse modeling approach. Limnol. Oceanogr. 46, 164-177.

Meile, C., Van Cappellen, P., 2005. Particle age distributions and $\mathrm{O}_{2}$ exposure times: timescales in bioturbated sediments. Global Biogeochem. Cycles 19, GB3013.

Naylor, C., Davison, W., Motelica-Heino, M., van den Berg, G.A., Van Der Heijdt, L.M., 2004. Simultaneous release of sulfide with Fe, Mn, $\mathrm{Ni}$ and $\mathrm{Zn}$ in marine harbour sediment measured using a combined metal/sulfide DGT probe. Sci. Total Environ. 328, 275-286.

Pallud, C., Van Cappellen, P., 2006. Kinetics of microbial sulfate reduction in estuarine sediments. Geochim. Cosmochim. Acta 70, $1148-1162$.

Peretyazhko, T., Van Cappellen, P., Meile, C., Coquery, M., Musso, M., Regnier, P., Charlet, L., 2005. Biogeochemistry of major redox elements and mercury in a tropical reservoir lake (Petit Saut, French Guiana). Aquat. Geochem. 11, 33-55.

Pilson, M.E.Q., 1998. An Introduction to the Chemistry of the Sea. Prentice Hall, Upper Saddle River, New Jersey.

Poulton, S.W., Krom, M.D., Raiswell, R., 2004. A revised scheme for the reactivity of iron (oxyhydr)oxide minerals towards dissolved sulfide. Geochim. Cosmochim. Acta 68, 3703-3715.

Regnier, P., Jourabchi, P., Slomp, C.P., 2003. Reactive-transport modeling as a technique for understanding coupled biogeochemical processes in surface and subsurface environments. Geol. Mijnbouw 82, 5-18.

Regnier, P., O'Kane, J.P., Steefel, C.I., Vanderborght, P., 2002. Modeling complex multi-component reactive-transport systems: towards a simulation environment based on the concept of a Knowledge Base. Appl. Math. Model. 26, 913-927.

Reinhold-Dudok van Heel, H.C., den Besten, P.J., 1999. The relation between macroinvertebrate assemblages in the Rhine-Meuse delta (The Netherlands) and sediment quality. Aquat. Ecosyst. Health Manag. 2, 19-38.

Revsbech, N.P., 1989. Diffusion characteristics of microbial communities determined by use of oxygen microsensors. J. Microbiol. Methods $\mathbf{9}$, $111-122$.

Rickard, D., 1997. Kinetics of pyrite formation by the H2S oxidation of iron (II) monosulfide in aqueous solutions between 25 and $125^{\circ} \mathrm{C}$ : the rate equation. Geochim. Cosmochim. Acta 61, 115134.
Roychoudhury, A.N., Van Cappellen, P., Kostka, J.E., Viollier, E., 2003. Kinetics of microbially mediated reactions: dissimilatory sulfate reduction in saltmarsh sediments (Sapelo Island, Georgia, USA). Estuar. Coast. Shelf Sci. 56, 1001-1010.

Sarazin, G., Michard, G., Prevot, F., 1999. A rapid and accurate spectroscopic method for alkalinity measurements in sea water samples. Water Res. 33, 290-294.

Smit, H., Reinhold-Dudok van Heel, H.C., Wiersma, S.M., 1995. Sublittoral macrozoobenthic assemblages in the enclosed sedimentpolluted Rhine-Meuse Delta; their relationship to environmental conditions. Neth. J. Aquat. Ecol. 29, 31-47.

Smit, H., Smits, R., van der Velde, G., Coops, H., 1997. Ecosystem responses in the Rhine-Meuse delta during two decades after enclosure and steps toward estuary restoration. Estuaries 20, 504-520.

Stephens, M.P., Kadko, D.C., Smith, C.R., Latasa, M., 1997. Chlorophyll- $a$ and pheopigments as tracers of labile organic carbon at the central equatorial Pacific seafloor. Geochim. Cosmochim. Acta 61, 4605-4619.

Sun, M., Aller, R.C., Lee, C., 1991. Early diagenesis of chlorophyll- $a$ in Long Island Sound sediments: a measure of carbon flux and particle reworking. J. Mar. Res. 49, 379-401.

Sun, M., Aller, R.C., Lee, C., 1994. Spatial and temporal distributions of sedimentary chloropigments as indicators of benthic processes in Long Island Sound. J. Mar. Res. 52, 149-176.

Sweerts, J.-P.R.A., Bar-Gilissen, M.-J., Cornelese, A.A., Cappenberg, T.E., 1991. Oxygen-consuming processes at the profundal and littoral sediment-water interface of a small meso-eutrophic lake (Lake Vechten, The Netherlands). Limnol. Oceanogr. 36, 1124 1133.

Teasdale, P.R., Hayward, S., Davison, W., 1999. In situ, highresolution measurement of dissolved sulfide using diffusive gradients in thin films with computer-imaging densitometry. Anal. Chem. 71, 2186-2191.

Thomsen, U., Thamdrup, B., Stahl, D.A., Canfield, D.E., 2004. Pathways of organic carbon oxidation in a deep lacustrine sediment, Lake Michigan. Limnol. Oceanogr. 4 (6), 2046-2057.

Tromp, T.K., Van Cappellen, P., Key, R.M., 1995. A global model for the early diagenesis of organic carbon and organic phosphorus in marine sediments. Geochim. Cosomchim. Acta. 59, 1259-1284.

Urban, N.R., Brezonik, P.L., Baker, L.A., Sherman, L.A., 1994. Sulfate reduction and diffusion in sediments of Little Rock Lake, Wisconsin. Limnol. Oceanogr. 3 (4), 797-815.

Van Cappellen, P., Wang, Y., 1995. Metal Cycling in surface sediments: modeling the interplay of transport and reaction. In: Allen, H.E. (Ed.), Metal Contaminated Sediments. Ann Arbor Press, Chelsea, MI, pp. 21-64.

Van Cappellen, P., Wang, Y.F., 1996. Cycling of iron and manganese in surface sediments: a general theory for the coupled transport and reaction of carbon, oxygen, nitrogen, sulfur, iron, and manganese. Am. J. Sci. 296, 197-243.

van den Berg, G.A., Buykx, S.E.J., van den Hoop, M., van der Heijdt, L.M., 2001. Vertical profiles of trace metals and acid-volatile sulphide in a dynamic sedimentary environment: Lake Ketel, The Netherlands. Appl. Geochem. 16, 781-791.

van den Berg, G.A., Loch, J.P.G., van der Heijdt, L.M., Zwolsman, J.J.G., 1998. Vertical distribution of acid-volatile sulfide and simultaneously extracted metals in a recent sedimentation area of the river meuse in The Netherlands. Environ. Toxicol. Chem. 17, 758-763.

van den Berg, G.A., Loch, J.P.G., van der Heijdt, L.M., Zwolsman, J.J.G., 1999. Mobilisation of heavy metals in contaminated sediments in the river Meuse, The Netherlands. Water Air Soil Pollut. 116, 567-586.

van den Berg, G.A., Loch, J.P.G., van der Heijdt, L.M., Zwolsman, J.J.G., 2000. Redox processes in recent sediments of the river Meuse, The Netherlands. Biogeochemistry 48, 217 235.

van Wijngaarden, M., Venema, L.B., De Meijer, R.J., Zwolsman, J.J.G., Van Os, B., Gieske, J.M.J., 2002. Radiometric sand-mud character- 
isation in the Rhine-Meuse estuary part A. Fingerprinting. Geomorphology 43, 87-101.

Wang, X.S., Matisoff, G., 1997. Solute transport in sediments by a large freshwater oligochaete, Branchiura sowerbyi. Environ. Sci. Technol. 31, 1926-1933.

Wersin, P., Hohener, P., Giovanoli, R., Stumm, W., 1991. Early diagenetic influences on iron transformations in a fresh-water lake sediment. Chem. Geol. 90, 233-252.
Westrich, J.T., Berner, R.A., 1984. The role of sedimentary organic matter in bacterial sulfate reduction: the G-model tested. Limnol. Oceanogr. 29, 236-249.

Wetzel, R.G., 2001. Limnology: Lake and River Ecosystems. Academic Press, San Diego.

Wijsman, J.W.M., Herman, P.M.J., Middelburg, J.J., Soetaert, K., 2002. A model for early diagenetic processes in sediments of the continental shelf of the Black Sea. Estuar. Coast. Shelf Sci. 54, 403-421. 